Research Article

\title{
Predicting Fatigue Life for Finite Line Contact under Starved Elastohydrodynamic Lubrication Condition
}

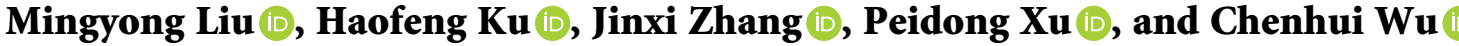 \\ Hubei Agricultural Machinery Engineering Research and Design Institute, Hubei University of Technology, \\ Wuhan 430068, China \\ Correspondence should be addressed to Mingyong Liu; lmy8508@qq.com
}

Received 2 September 2019; Revised 26 October 2019; Accepted 20 November 2019; Published 22 January 2020

Academic Editor: Jose de Jesus Rubio

Copyright $(92020$ Mingyong Liu et al. This is an open access article distributed under the Creative Commons Attribution License, which permits unrestricted use, distribution, and reproduction in any medium, provided the original work is properly cited.

Surface contact fatigue is the main failure mode in many mechanical components, such as gears, bearings, and cam-followers. A fatigue life prediction model is proposed for finite line contact under starved thermal elastohydrodynamic lubrication (TEHL) condition in this paper. Then, the effects of inlet oil-supply thickness, slide-to-roll ratio (SRR), and operating conditions on the lubrication performance and fatigue life are investigated. The results show that the lubrication characteristics and fatigue life of finite line contact are obviously different from those of fully flooded situation by introducing the starved lubrication condition. For example, the severe starved conditions lead to a significant increase in friction coefficient and decreased fatigue life. The variation of SRR has an important influence on the fatigue life. With the increase of SRR, the fatigue life decreases firstly and then increases. The stress concentration occurs near the surface when speed is low. In addition, under the low-speed situation, rotation speed variation has little effect on the fatigue life.

\section{Introduction}

With the development of engineering machinery to high speed and heavy load, the starved situation widely exists in many mechanical components. Oil shortage may cause a series of contact failure situations. For instance, starved lubrication makes the contact interface become a mixed lubrication situation. Starved lubrication will also reduce the contact pair transmission performance and mechanical efficiency. This will not only have economic losses but may also result in mechanical equipment failures and even safety accidents. In order to effectively improve the lubrication performance of contact pairs, it is necessary to investigate the lubrication characteristics of contact pairs under the starved lubrication condition.

In the past two decades, a number of numerical and experimental results on the starved EHL have been reported. Wedeven et al. [1] measured the EHL oil film for a rolling point contact under starvation conditions using an optical interferometer. Chevalier et al. [2] proposed a numerical model for starved EHL point contact and studied the effect of inlet supply starvation on film thickness whilst adopting the amount of oil present on the surface as a means of defining the degree of starvation. Based on Elrod's algorithm [3], Yang et al. [4] established a thermal and non-Newtonian EHL model for starved EHL line contact and proposed the concept of optimal oil supply in the inlet region. Yin et al. [5] developed a starved thermal EHL model in elliptical contact based on the multigrid technique and analyzed the influence of ellipticity ratio, thickness of oil-supply layer, slide-to-roll ratio (SRR), and so forth on the lubrication behaviour. Liu and Yang [6] studied the effect of oil-supply conditions for the finite line contact and pointed out that the optimum quantity of the supplied oil was very important for the contact pair. Wang et al. [7] established a mixed EHL model for point contact with consideration of the inlet starvation and discussed the effect of texture surface on the lubrication performance. Mihailidis et al. [8] discussed the effect of working conditions and end shape modification on lubrication performance for the non-Newtonian starved thermal EHL of a finite line contact. Parinam and Karan [9] conducted a starved EHL line contact model for lubricants with 
linear pressure-viscosity relationship. Masjedi and Khonsari [10] conducted a starved mixed EHL model for line and point contacts considering the surface roughness and studied the influence of starved oil on the interaction of oil film thickness and surface roughness. Zhu et al. [11] established a deterministic mixed EHL model of finite roller contact involving realistic surface roughness and studied the effect of roller length and crown radius on the film thickness, subsurface stress field, and so on. Torabi et al. [12] proposed a mixed EHL model of a finite length cam and follower mechanism considering surface roughness and studied the influence of thermal effects, end leakage, and roughness on the friction performance. Liu et al. [13] established a mixed EHL model of a finite line contact by using realistic surface roughness and predicted the influence of working conditions and lubrication parameters on the fatigue life. Liu et al. $[14,15]$ developed a starved EHL model for a spur gear pair and discussed the influence of working condition parameters on the friction coefficient and mechanical power loss. $\mathrm{Pu}$ et al. [16] investigated the starved mixed EHL model for point contact with arbitrary entrainment angle and discussed the effect of arbitrary entrainment angle on the friction and flash temperature.

As mentioned above, the theoretical study of starved EHL for line and point contact has been wildly reported in the last $10-15$ years. However, there are few studies on the lubrication of starved thermal EHL in finite line contact and even less on the fatigue life of contact pairs. In engineering, spur and helical gear pairs, various bearings, cam-follower systems, and so on belong to the finite contact model. In order to reveal the information on lubrication of finite line contact under the starvation condition, a starved thermal EHL model of finite line contact has been established in the paper. The effects of working conditions and inlet oil-supply condition on the lubrication characteristics and pitting life are discussed.

\section{Model Formulations}

2.1. Geometrical and Kinematic Analysis. In practical engineering, the contact pairs such as spur and helical gear pairs, cam-follower, and bearing can be simulated as two rollers with finite length. As shown in Figure 1, this model can be further simplified as the contact model between an equivalent cylindrical roller and a plane. The radius of the equivalent cylindrical roller is $R_{x}$.

For the two cylindrical rollers shown in Figure 1, the expression of the geometric gap between solid surfaces can be defined as follows.

The straight generatrix segment is

$$
h_{g}=\frac{x^{2}}{2 R_{1}}+\frac{x^{2}}{2 R_{2}}=\frac{x^{2}}{2 R_{x}} .
$$

The end-modified segment is

$$
h_{g}=\frac{x^{2}}{2 R_{x}}+\frac{y^{2}}{2 r}
$$

where $1 / R_{x}=1 / R_{1}+1 / R_{2}$ and $1 / r=1 / r_{1}+1 / r_{2}$.
Since the two cylindrical rollers are rotating around their axes, the surface kinematic parameters, such as surface velocities $u_{1}$ and $u_{2}$, entrainment velocity $u_{\mathrm{e}}$, sliding velocity $u_{\mathrm{s}}$ and SRR $\xi$ can be obtained by kinematics analysis. These parameters can be expressed as

$$
\left\{\begin{array}{l}
u_{1}=R_{1} \omega_{1}, \\
u_{2}=R_{2} \omega_{2}, \\
u_{e}=\frac{\left(u_{1}+u_{2}\right)}{2}, \\
u_{s}=u_{1}-u_{2}, \\
\xi=\frac{u_{s}}{u_{e}},
\end{array}\right.
$$

where $\omega_{1}$ and $\omega_{2}$ are the angular velocities of rollers 1 and 2, respectively.

For starved situation, the lubrication enters the contact zone mainly by attaching to two solid surfaces. In order to describe the inlet supply oil condition conveniently, the equivalent oilsupply film thickness $h_{\text {oil }}$ has been introduced. The expression of $h_{\mathrm{oil}}$ is consistent with the findings of Yin et al. [5].

2.2. Starved TEHL Model for Finite Line Contact. The starved thermal EHL model of finite line contact is based upon the fully flooded thermal EHL model developed by Yang and Wen [17]. The parameter $\theta$ used to describe the starvation condition has been embedded in the Reynolds equation. The modified Reynolds equation accounting for non-Newtonian fluid behaviour can be expressed as

$$
\frac{\partial}{\partial x}\left[\left(\frac{\rho}{\eta}\right)_{e} h^{3} \frac{\partial p}{\partial x}\right]+\frac{\partial}{\partial y}\left[\left(\frac{\rho}{\eta}\right)_{e} h^{3} \frac{\partial p}{\partial y}\right]=12 u_{e} \frac{\partial}{\partial x}\left(\rho^{*} \theta h\right),
$$

where

$$
\begin{aligned}
\left(\frac{\rho}{\eta}\right)_{e} & =12\left(\frac{\eta_{e} \rho_{e}^{\prime}}{\eta_{e}^{\prime}}-\rho_{e}^{\prime \prime}\right), \\
\rho^{*} & =\frac{\left[\rho_{e}^{\prime} \eta_{e}\left(u_{2}-u_{1}\right)+\rho_{e} u_{1}\right]}{u_{e}}, \\
\rho_{e} & =\frac{1}{h} \int_{0}^{h} \rho \mathrm{d} z, \\
\rho_{e}^{\prime} & =\frac{1}{h^{2}} \int_{0}^{h} \rho \int_{0}^{z} \frac{\mathrm{d} z^{\prime}}{\eta^{*}} \mathrm{~d} z, \\
\rho_{e}^{\prime \prime} & =\frac{1}{h^{3}} \int_{0}^{h} \rho \int_{0}^{z} \frac{z^{\prime} \mathrm{d} z^{\prime}}{\eta^{*}} \mathrm{~d} z, \\
\frac{1}{\eta_{e}} & =\frac{1}{h} \int_{0}^{h} \frac{\mathrm{d} z}{\eta^{*}}, \\
\frac{1}{\eta_{e}^{\prime}} & =\frac{1}{h^{2}} \int_{0}^{h} \frac{z \mathrm{~d} z}{\eta^{*}} .
\end{aligned}
$$




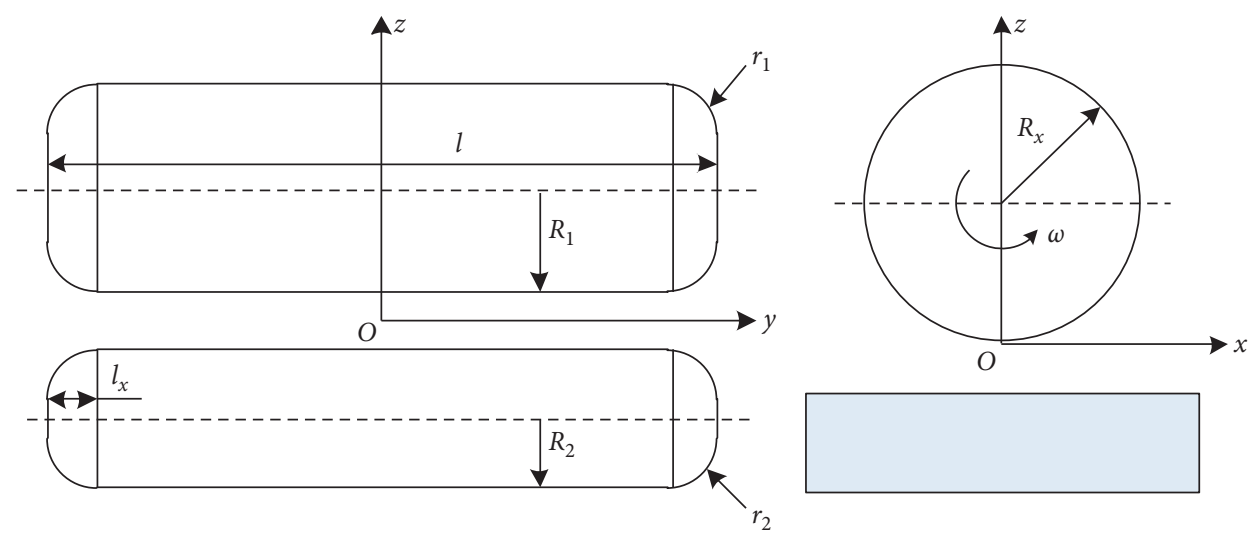

Figure 1: A finite line contact model.

In equation (3), $p$ is the pressure, $h$ is the total geometric gap, $\rho$ is the density of lubricant, and $\eta^{*}$ is the equivalent viscosity for non-Newtonian fluid. The parameter $\theta$ is the partial oil film ratio and is given as

$$
\theta(x, y)=\frac{h_{f}(x, y)}{h(x, y)}
$$

where $h_{\mathrm{f}}$ is the film thickness.

Moreover, the modified Reynolds equation should also satisfy the following condition:

$$
p(x, y)[1-\theta(x, y)]=0 .
$$

In the equation (6), it is revealed that, at the region $p>0.0, \theta=1.0$ represents the fully flooded region, while at the $p=0.0,0.0<\theta<1.0$ represents the starved region. The boundary conditions of equation (3) can be expressed as

$$
\left\{\begin{array}{l}
p\left(x_{\text {in }}, y\right)=p\left(x_{\text {out }}, y\right)=p\left(x, y_{\text {in }}\right)=p\left(x, y_{\text {out }}\right)=0, \\
p(x, y) \geq 0\left(x_{\text {in }}<x<x_{\text {out }}, y_{\text {in }} \leq y \leq y_{\text {out }}\right) .
\end{array}\right.
$$

The $x$-coordinate coincides with the motion direction. The end modification is considered. So, the instantaneous total gap can be calculated by the following expression:

$$
\begin{aligned}
h(x, y)= & h_{00}+\frac{x^{2}}{2 R_{x}}+\frac{(y-0.5 l)^{2}}{2 r} f_{\Delta} \\
& +\frac{2}{\pi E^{\prime}} \iint_{\Omega} \frac{p\left(x^{\prime}, y^{\prime}\right)}{\sqrt{\left(x-x^{\prime}\right)^{2}+\left(y-y^{\prime}\right)^{2}}} \mathrm{~d} x^{\prime} \mathrm{d} y^{\prime},
\end{aligned}
$$

where $h_{00}$ is the normal approach of two surfaces. If $|y| \geq 0.5 l, f_{\Lambda}=1$, and if $|y|<0.5 l, f_{\Lambda}=0$.

The applied load must be balanced by the contact pressure over the entire solution domain. The equation is written as

$$
\iint_{\Omega} p(x, y) \mathrm{d} x \mathrm{~d} y=F .
$$

The viscosity and density of the lubricant are specified using the Roelands equation [18] and the
Dowson-Higginson equation [19], respectively. These equations are as follows:

$$
\begin{aligned}
& \eta=\eta_{0} \exp \left\{A_{1}\left[\left(1+A_{2} p\right)^{z_{0}}\left(A_{3} T-A_{4}\right)^{-s_{0}}-1\right]\right\}, \\
& \rho=\rho_{0}\left[1+\frac{C_{1} p}{\left(1+C_{2} p\right)}-C_{3}\left(T-T_{0}\right)\right]
\end{aligned}
$$

where $A_{1}=\ln \left(\eta_{0}\right)+9.67, \quad A_{2}=5.1 \times 10^{-9} \mathrm{~Pa}^{-1}, \quad A_{3}=1 /$ $\left(T_{0}-138\right) K^{-1}, \quad A_{4}=138 /\left(T_{0}-138\right), \quad z_{0}=\alpha /\left(A_{1} \cdot A_{2}\right)$, $C_{1}=0.6 \times 10^{-9} \mathrm{~Pa}^{-1}, \quad C_{2}=1.7 \times 10^{-9} \mathrm{~Pa}^{-1}, \quad$ and $C_{3}=$ $0.0007 K^{-1} \cdot \eta_{0}$ is the ambient viscosity of lubricant, $\rho_{0}$ is the ambient density of lubricant, and $T_{0}$ is the ambient temperature.

The equivalent viscosity has been introduced in equation (3) to describe the non-Newtonian fluid behaviour. In this paper, the Eyring fluid has been adopted [20]. So, the equivalent viscosity is given as

$$
\eta^{*}=\eta \frac{\tau / \tau_{0}}{\sinh \left(\tau / \tau_{0}\right)}
$$

where $\tau_{0}$ is the characteristic shear stress and $\tau_{x}$ is the surface shearing stress along the direction of entrainment velocity.

Due to the additional sliding movement along the two surfaces, the thermal effects should be considered. For the steady-state TEHL problem, the thermal conductivity along $x$ and $y$ directions is neglected. The energy equation of fluid reads

$$
\begin{aligned}
c_{f}\left(\rho u_{f} \frac{\partial T}{\partial x}+\rho v_{f} \frac{\partial T}{\partial y}-q \frac{\partial T}{\partial z}\right)= & k_{f} \frac{\partial^{2} T}{\partial z^{2}}-\frac{T}{\rho} \frac{\partial \rho}{\partial T}\left(u_{f} \frac{\partial p}{\partial x}+v_{f} \frac{\partial p}{\partial y}\right) \\
& +\eta^{*}\left[\left(\frac{\partial u_{f}}{\partial z}\right)^{2}+\left(\frac{\partial v_{f}}{\partial z}\right)^{2}\right],
\end{aligned}
$$

where $u_{f}$ and $v_{f}$ are the velocity of fluid along the $x$ and $y$ direction. $c_{f}$ and $k_{f}$ are the specific heat of lubricant and thermal conductivity, respectively. In addition,

$$
q=\frac{\partial}{\partial x} \int_{0}^{z} \rho u_{f} \mathrm{~d} z^{\prime}+\frac{\partial}{\partial y} \int_{0}^{z} \rho v_{f} \mathrm{~d} z^{\prime}
$$


Heat conduction is mainly considered in two cylindrical rollers solid. The solid energy equations are expressed as

$$
\left\{\begin{array}{c}
c_{1} \rho_{1} u_{1} \frac{\partial T}{\partial x}=k_{1} \frac{\partial^{2} T}{\partial z_{1}^{2}} \\
c_{2} \rho_{2} u_{2} \frac{\partial T}{\partial x}=k_{2} \frac{\partial^{2} T}{\partial z_{2}^{2}}
\end{array}\right.
$$

where $c_{1}$ and $c_{2}$ are the specific heats of solids and $k_{1}$ and $k_{2}$ are the thermal conductivities of solids.

The interface continuity equation is

$$
\left\{\begin{array}{l}
\left.k_{1} \frac{\partial T}{\partial z_{1}}\right|_{z_{1}=0}=\left.k_{f} \frac{\partial T}{\partial z}\right|_{z=h / 2} \\
\left.k_{2} \frac{\partial T}{\partial z_{2}}\right|_{z_{2}=0}=\left.k_{f} \frac{\partial T}{\partial z}\right|_{z=-h / 2}
\end{array}\right.
$$

where $z_{1}$ and $z_{2}$ are the coordinates in solids 1 and 2, with the same direction of $z$.

The traction force and friction coefficient on the two surfaces can be calculated as follows:

$$
\begin{array}{r}
\left\{f_{x_{1,2}}=\iint_{\Omega} \tau_{x} \mathrm{~d} x \mathrm{~d} y, f_{y_{1,2}}=\iint_{\Omega} \tau_{y} \mathrm{~d} x \mathrm{~d} y,\right. \\
\mu_{f}=\frac{1}{2 F}\left(\sqrt{f_{x_{1}}^{2}+f_{y_{1}}^{2}}+\sqrt{f_{x_{2}}^{2}+f_{y_{2}}^{2}}\right) .
\end{array}
$$

2.3. Fatigue Life Prediction Model. In general, the existing fatigue models can be divided into three groups, i.e., stressbased model, strain-based model, and energy-based model. For the high-cycle fatigue problems, such as gear and bearings, the stress-based model is popularly used in the high-cycle fatigue analysis. Qiao et al. [21] compared a variety of stress-based fatigue models under mixed EHL situation and claimed that critical plane-based multiaxial fatigue criteria and cumulative damage theory yielded the similar predictions. In the current study, the stress-based fatigue life model proposed by Zaretsky [22] has been utilized for fatigue life prediction. This fatigue model has been widely adopted by the other research groups $[11,13,21]$. The model can be expressed as

$$
\ln \frac{1}{S} \sim N^{e} \cdot \int_{V} \tau_{m}^{e \cdot c} \mathrm{~d} V,
$$

where $S$ is the probability of survival, $N$ is the fatigue life, $\tau_{\mathrm{m}}$ is the equivalent stress, $e$ is the Weibull slope, $c$ is the stress exponent, and $V$ is the stress volume. In the present study, $S=0.95, e=1.1$, and $c=4.5$.

As shown in equation (17), in order to establish a stressbased fatigue life prediction model, the equivalent stress needs to be defined. In this paper, von Mises stress is adopted as the stress criterion.

\section{Numerical Method and Model Validation}

In Section 2, the governing equations form a differentialintegral system. The differential scheme adopted in this paper is based on that given by Liu et al. [23]. For example, for the Reynolds equation, the Poiseuille flows are discretized by the second-order central differential scheme. The second-order backward scheme has been adopted for the couette flow. The elastic deformation and stress field are calculated through the discrete convolution and fast Fourier transform (DC-FFT) method [24]. As conduction in the $x$ and $y$ directions is not induced, the temperature field can be updated using the marching method $[4,25]$. The boundary between pressure area and starved-oil area is determined automatically by the Elrod algorithm [3]. In order to obtain the convergent results of pressure and partial oil film ratio, the flow chart of the numerical process in Ref. $[4,5]$ has been adopted. As described in Ref. [4, 5], the pressure and the partial oil film ratio are treated as separate variables in a Gauss-Seidel line relaxation. The nominal Hertzian contact parameters $p_{\mathrm{H}}$ and $b$ at the middle section are introduced into the dimensionless analysis, as $P=p / p_{\mathrm{H}}, H=h R_{\mathrm{x}} / b^{2}$, $X=x / b$, and $Y=y / b$, and in the most of the cases reported here, the dimensionless calculation domain is chosen as $X=$ $[-4.0,2.0]$ and $Y=[-l / 2 b, l / 2 b]$. There are $256 \times 512$ equally spaced nodes in the $x$ and $y$ directions. For calculation of the temperature field, there are 15 equally spaced grid nodes across the film thickness and 10 nodes inside each solid. In order to capture the variation of stress field inside the solid, the number of grid nodes is 32 . The iterative process is completed while the relative error of pressure, load, and thermal field are less than $10^{-5}, 10^{-4}$, and $10^{-5}$, respectively.

In order to validate the accuracy of the current model, the numerical results of the proposed model have been compared to the published data of Liu and Yang [6]. The corresponding calculation parameters are selected as $W=1.968 \times 10^{-5}$, $U_{\mathrm{e}}=6.0 \times 10^{-11}, h_{\mathrm{oil}}=0.9 \mu \mathrm{m}, R_{\mathrm{x}}=12.7 \mathrm{~mm}, r=4 \mathrm{~mm}, l=$ $14.7 \mathrm{~mm}$, and $l_{x}=1 \mathrm{~mm}$. The comparisons of pressure and film thickness on the plane of $Y=0$ between the present model and Liu and Yang's results are shown in Figure 2. It reveals that the agreement between the current study and Liu and Yang's results is satisfactory. Due to the differences between the algorithm adopted in this paper and the reference paper, the numerical solutions may be slightly different, but the correctness of the algorithm and model in this paper can be fully verified.

\section{Results and Discussion}

4.1. A Preliminary Starved TEHL Results for Finite Line Contact. In this paper, the relevant parameters about finite line contact pair geometry, operating condition, and lubrication are listed in Table 1. The inlet oil-supply thickness is set as $1.0 \mu \mathrm{m}$. Based on the proposed model, a typical starved TEHL result for finite line contact has been obtained. The three-dimensional distributions of pressure $p$, film thickness $h_{f}$, oil film temperature $T_{f}$, and partial oil film ratio $\theta$ are shown in Figures 3(a)3(d). The corresponding results of $p$ and $T_{f}$ on the section $y=0$ are also plotted in Figures 3(e)-3(f).

As shown in Figure 3, it is revealed that the distribution of pressure and oil film temperature is similar. In the inlet starved region, the pressure is equal to zero and the film 


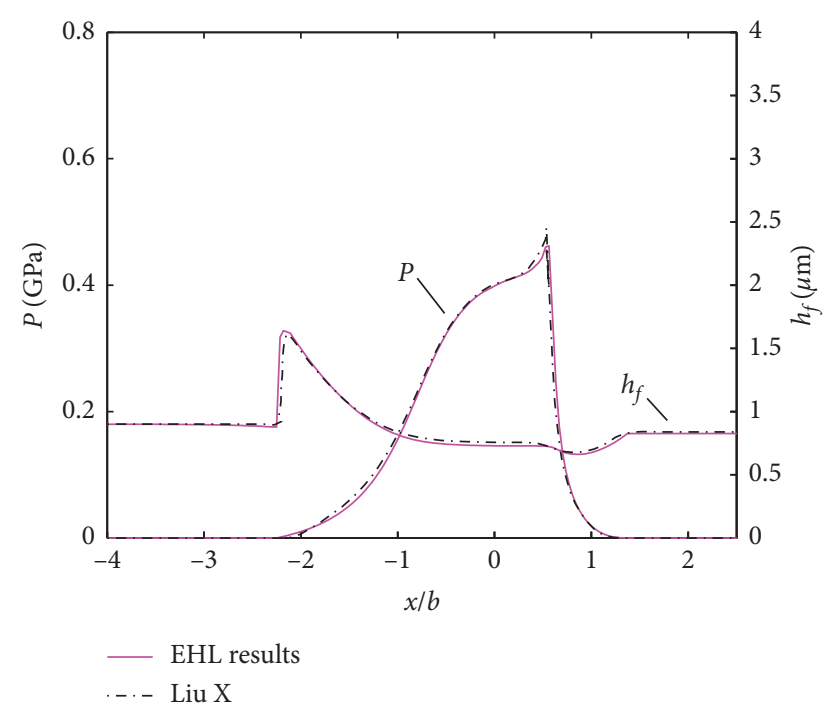

Figure 2: Comparison EHL results between the current study and Liu and Yang's results [6].

TABLE 1: Relevant parameters of finite line contact pair and lubrication.

\begin{tabular}{lc}
\hline Parameters & Specification \\
\hline Ambient viscosity of lubricant, $\eta_{0}(\mathrm{~Pa} \cdot \mathrm{s})$ & 0.08 \\
Ambient density of lubricant, $\rho_{0}\left(\mathrm{~kg} / \mathrm{m}^{3}\right)$ & 870 \\
Density of solids, $\rho_{1,2}\left(\mathrm{~kg} / \mathrm{m}^{3}\right)$ & 7850 \\
Specific heat of lubricant, $c_{f}\left(\mathrm{~J} \cdot \mathrm{Kg}^{-1} \mathrm{~K}^{-1}\right)$ & 2000 \\
Specific heats of solids, $c_{1,2}\left(\mathrm{~J} \cdot \mathrm{Kg}^{-1} \mathrm{~K}^{-1}\right)$ & 470 \\
Thermal conductivity of lubricant, $k_{f}\left(\mathrm{~W} \cdot \mathrm{m}^{-1} \mathrm{~K}^{-1}\right)$ & 0.14 \\
Thermal conductivities of solids, $k_{1,2}\left(\mathrm{~W} \cdot \mathrm{m}^{-1} \mathrm{~K}^{-1}\right)$ & 46 \\
Viscosity-pressure coefficient, $\left.\alpha(\mathrm{GPa})^{-1}\right)$ & 22 \\
Viscosity-temperature coefficient, $\beta_{T}\left(\mathrm{~K}^{-1}\right)$ & 0.0476 \\
Equivalent elastic modulus, $E^{\prime}(\mathrm{GPa})$ & 226 \\
Nominal Hertzian contact pressure, $p_{\mathrm{H}}(\mathrm{GPa})$ & 0.6 \\
Angular velocity of roller $1, \omega_{1}(\mathrm{rad} / \mathrm{s})$ & 183.3 \\
Ambient temperature, $T_{0}(\mathrm{~K})$ & 303 \\
Characteristic shear stress, $\tau_{0}(\mathrm{MPa})$ & 4 \\
Roller radius, $R_{1} / R_{2}(\mathrm{~mm})$ & $60 / 30$ \\
Modification radius, $r_{1} / r_{2}(\mathrm{~mm})$ & $30 / 20$ \\
Total length and modification length, $l / l_{x}(\mathrm{~mm})$ & $20.0 / 1.0$ \\
\hline
\end{tabular}

thickness maintains the value of inlet supply oil thickness. In effective pressure area, the lubricant fills the entire geometric gap and the corresponding partial oil film ratio is equal to 1.0, as shown in Figure 3(e). Meanwhile, due to the end effect, the pressure peak appears at both ends of contact line. Figure 3(f) illustrates that the temperature rise of film is higher than that of two surfaces.

4.2. Effect of Inlet Oil-Supply Thickness. Sometimes, the contact interface does not present a fully flooded condition. Furthermore, the excessive oil supply is unnecessary and may cause the additional energy loss $[5,6]$. The effect of inlet supply condition has been discussed. The corresponding working conditions are nominal Hertzian pressure $p_{\mathrm{H}}=0.6 \mathrm{GPa}$, angular velocity of roller $1 \omega_{1}=183.3 \mathrm{rad} / \mathrm{s}$, and the SRR $\xi=0.2$.
Figure 4 shows the variation of film thickness and friction coefficient with the inlet oil-supply thickness. It should be pointed out that $h_{\text {cen }}$ and $h_{\text {min }}$ represent the central film thickness and minimum film thickness on the section $y=0$. In Figure 4, the horizontal dotted lines represent the results of fully flooded condition on the section $y=0$. As shown in Figure 4, as the inlet oil-supply thickness goes up, the central and minimum film thicknesses increase firstly and then tend to the fully flooded results. The variation trend is consistent with Ref. [6]. Figure 4(a) reveals that the central and minimum film thicknesses increase with the increase of inlet oil-supply thickness at the range of $h_{\mathrm{oil}}<6.0 \mu \mathrm{m}$. When the inlet oil-supply thickness is more than $6.0 \mu \mathrm{m}$, the effects of $h_{\text {oil }}$ on the lubrication performance is insignificant. It indicates that the starved lubrication has been significantly improved. The corresponding variation of friction coefficient is shown in Figure 4(b). Figure 4(b) shows that, as the inlet oil-supply thickness increases, the friction coefficient decreases gradually and tends to the value of fully flooded situation. It reveals that starved lubrication leads to the deterioration of lubrication performance and can cause the contact to operate in the mixed EHL regime. So, it can be said that the optimal inlet oil-supply layer is about $6.0 \mu \mathrm{m}$ under the current case.

Figure 5 shows the distribution of pressure and film thickness on the section $y=0$ with different inlet oil-supply thicknesses. The corresponding fully flooded results have also been plotted in Figure 5. It can be seen that, as the inlet oil-supply thickness increases, the width of effective pressure is enlarged. Meanwhile, the second pressure peak increases and moves towards the inlet region. Figure 5(b) reveals that the film thickness contraction in the outlet region increases with the increase of inlet oil-supply thickness. As the inlet oil-supply thickness reaches the optimal value, the distribution of pressure and film thickness approaches the fully flooded result gradually.

Figure 6 shows the effect of inlet oil-supply thickness on the calculated fatigue life. It can be seen from Figure 6 that the calculated fatigue life increases firstly and then tends to the value of fully flooded case with the increase of the inlet oilsupply thickness. It indicates that the severe starved lubrication leads to the decrease of fatigue life. Figure 7 shows the von Mises stress field between starved lubrication and fully flooded lubrication. As shown in Figure 7, the inlet oil-supply thickness has a significant effect on the subsurface stress field. The region of higher stress locates at the subsurface. Due to the end effect, the stress concentration occurs at both ends of the contact line, as shown in Figures 7(d)-7(f). As the inlet oilsupply thickness increases, the higher stress moves towards to the outlet region on the section $y=0$, especially in the case of fully flooded. The distribution of stress field is consistent with the corresponding pressure as shown in Figure 5(a).

4.3. Effect of Slide-to-Roll Ratio. In general, the sliding movement exists widely on the surface of contact pairs, such as various gear pairs and cam-follower. In most situations, the SRR value may switch from negative to positive. In order to discuss the effects of SRR on the lubrication performance 


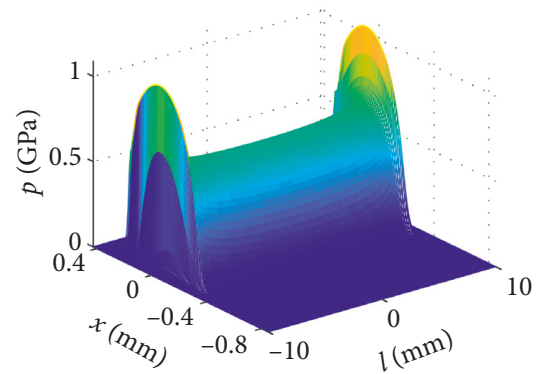

(a)

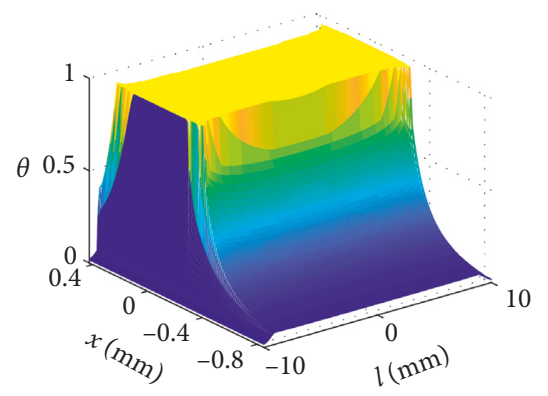

(d)

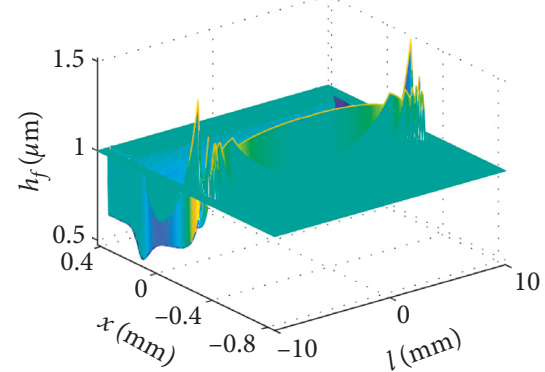

(b)

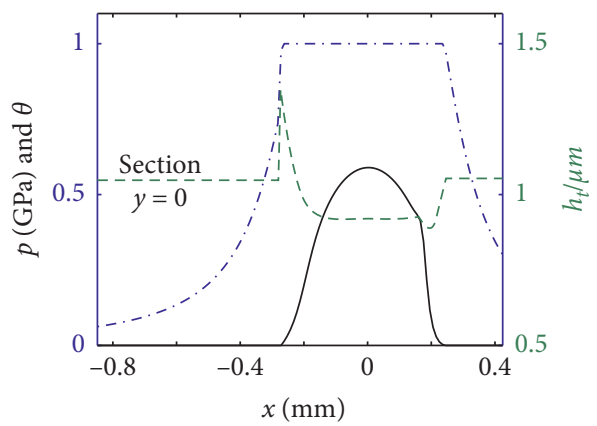

$-p$
$-\cdots \theta$
$--h_{f}$

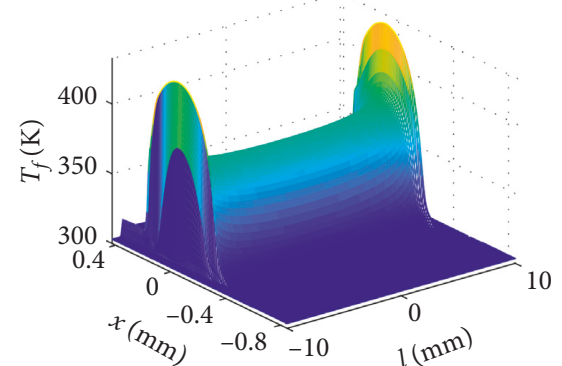

(c)

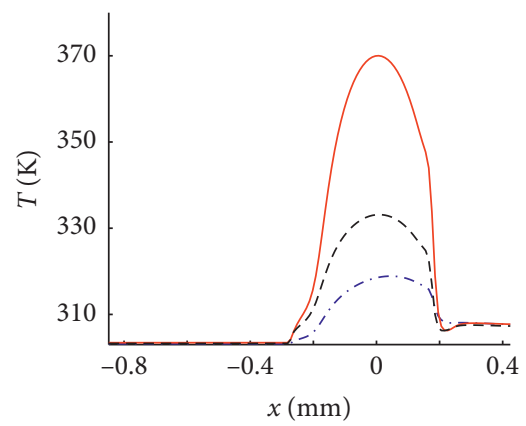

$\begin{aligned}-.- & T_{1} \\ - & T_{f} \\ --- & T_{2}\end{aligned}$

(e)

(f)

FIgURe 3: A typical starved TEHL results of finite line contact.

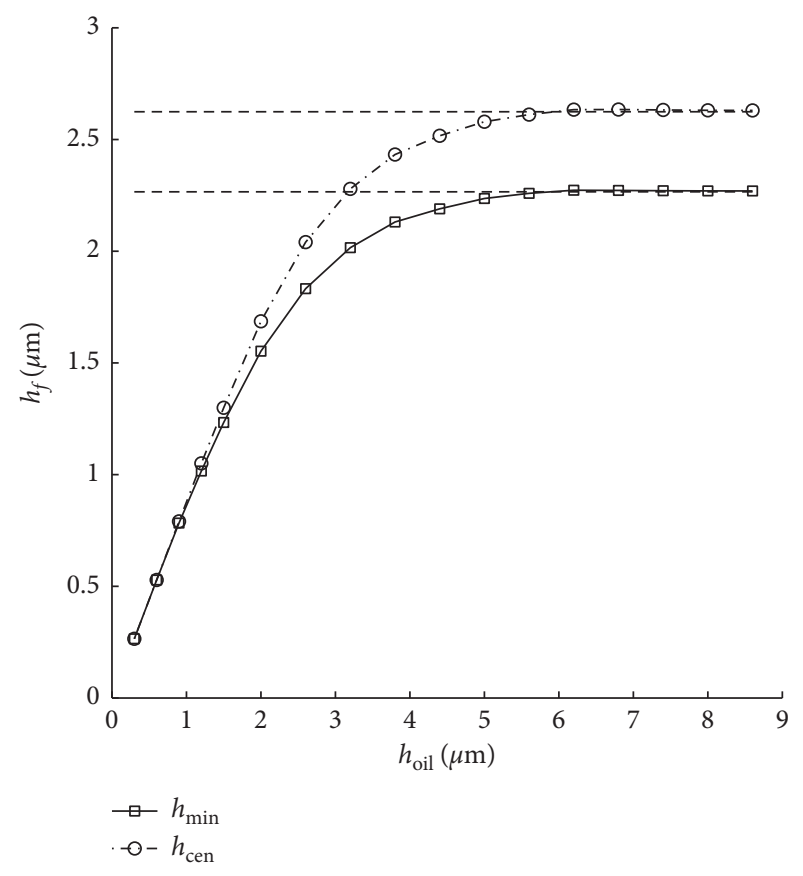

(a)

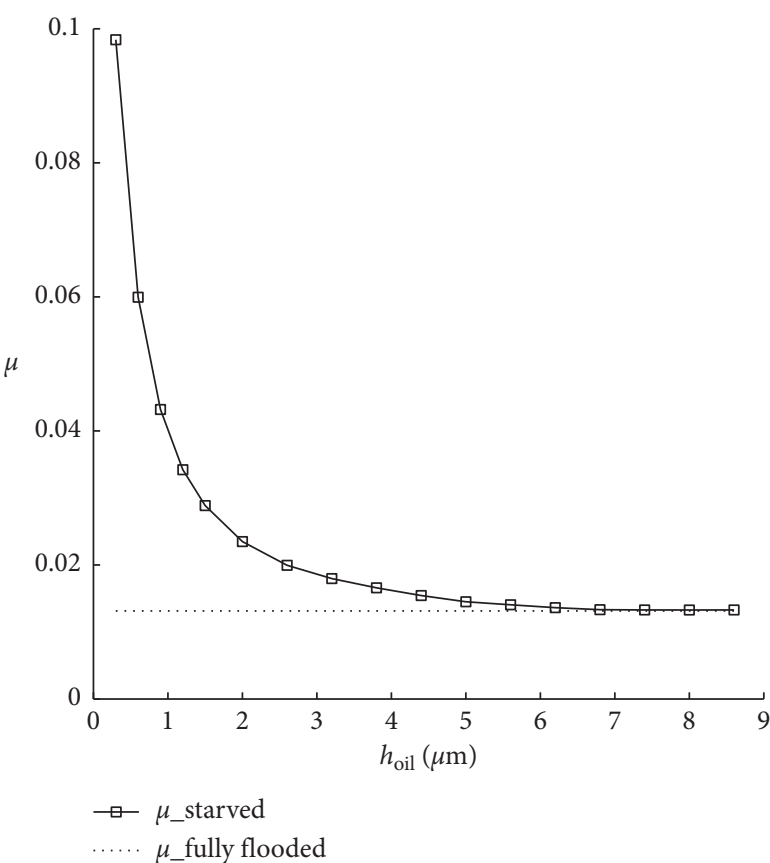

(b)

FIGURE 4: Variation of film thickness and friction coefficient versus the inlet oil-supply thickness.

and fatigue life, the selected working condition are $h_{\mathrm{oil}}=2.0 \mu \mathrm{m}$ and nominal Hertzian pressure $p_{\mathrm{H}}=0.6 \mathrm{GPa}$ in this section. The change range of SRR is -1.0 to 1.0 .
Figure 8 shows the influence of SRR on the film thickness and friction coefficient. Figure 8(a) illustrates that, as the absolute of SRR increases, the minimum film thickness 


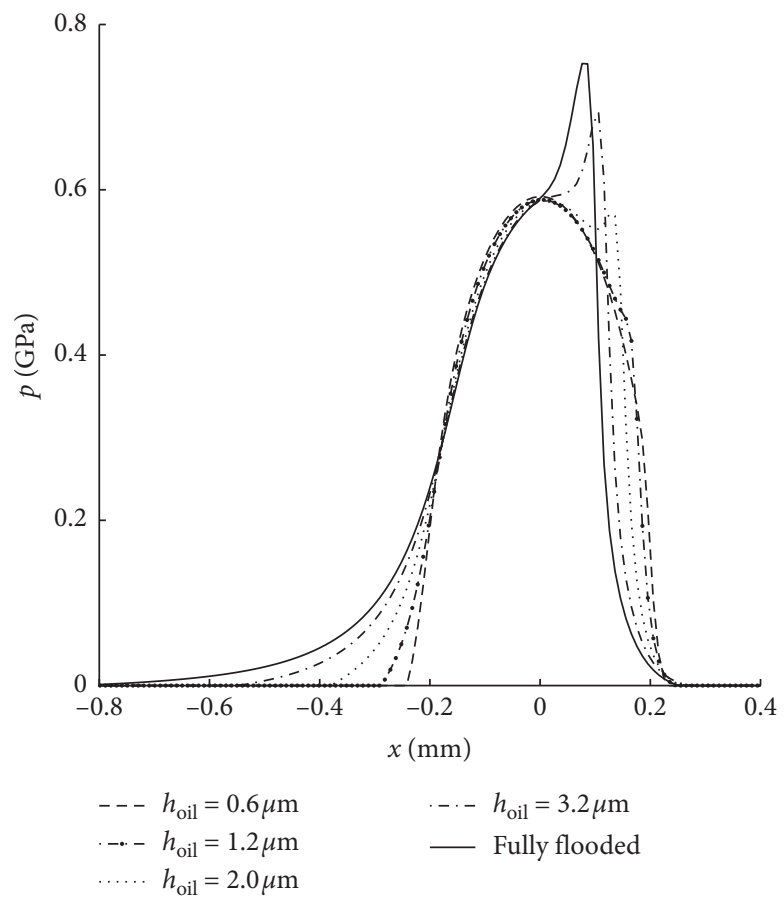

(a)

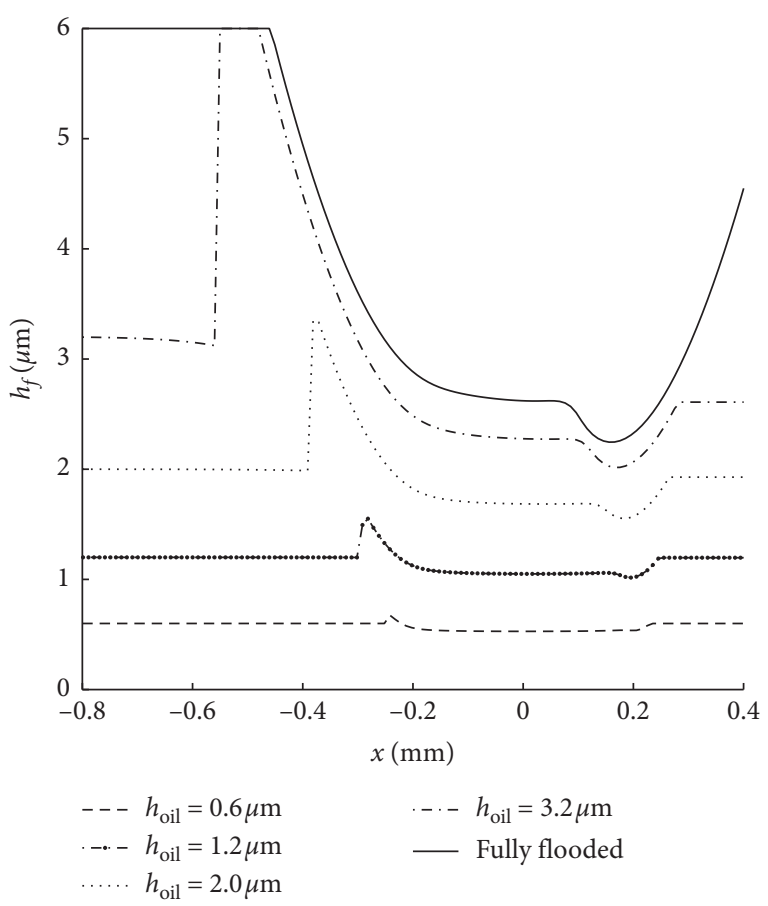

(b)

FIgURE 5: Distribution of pressure and film thickness with the different $h_{\text {oil }}$ on the section $y=0$.

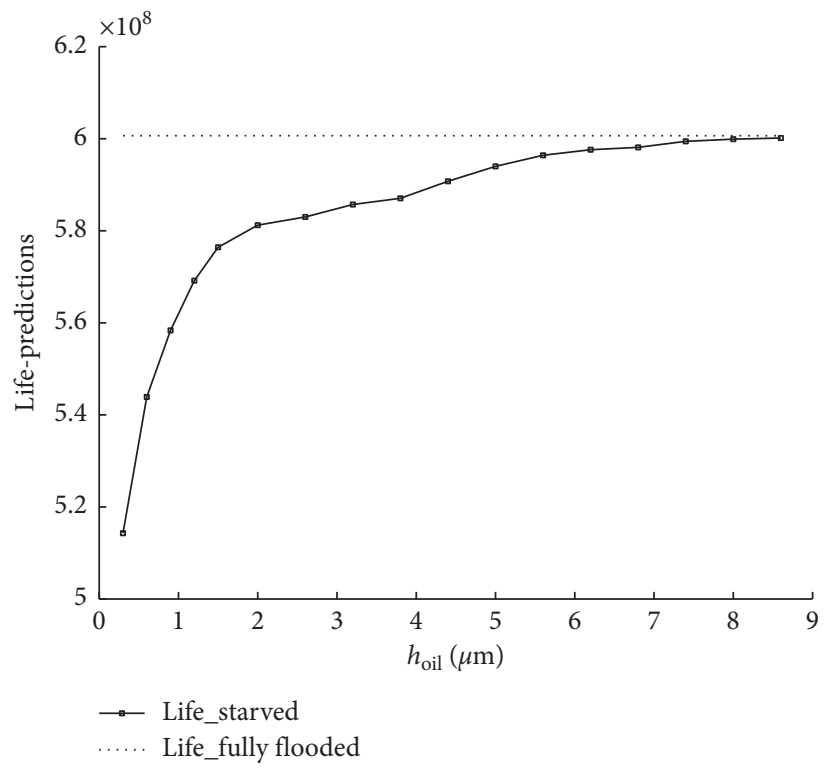

FIGURE 6: Effect of inlet oil-supply layer on the fatigue life.

decreases gradually. This may attribute it to as the SRR increases, the oil viscosity decreases with the increase of film temperature. Figure $8(\mathrm{~b})$ shows the variation of friction coefficient with the change of SRR. It indicates that both the friction coefficient and the SRR approach zero, i.e., during the pure rolling period. As the SRR magnitude increases from 0 to 1.0 , the friction coefficient increases firstly and then decreases. This is because when the SRR is small, the influence of temperature is weak and the viscosity does not reduce significantly in the Hertzian zone. With further increase of SRR value, the thermal effect becomes increasingly significant and the viscosity of lubricant decreases significantly.

Figure 9 plots the distribution of pressure and film thickness on the section $y=0$ with the inlet oil-supply thickness $h_{\text {oil }}=2.0 \mu \mathrm{m}$. It can be seen from Figure 9 that the second pressure peak grows with the increase of the slide-toroll ratio and moves towards the inlet region. The effective 


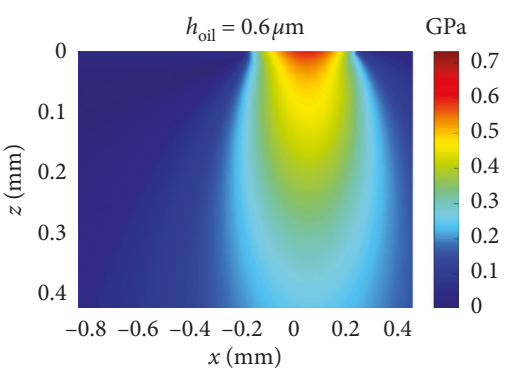

(a)

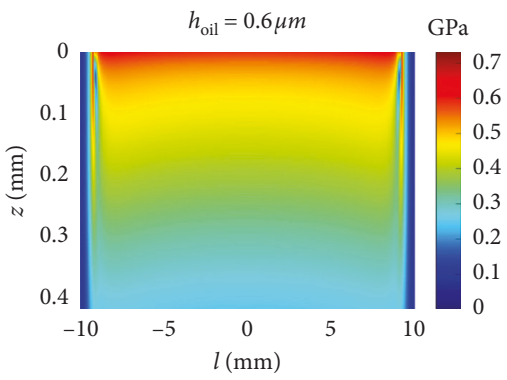

(d)

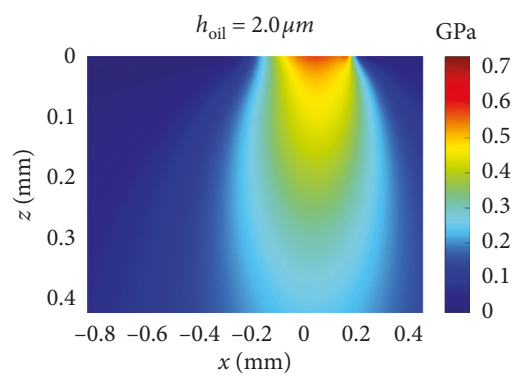

(b)

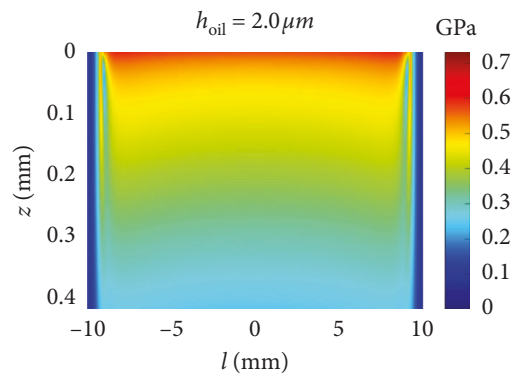

(e)

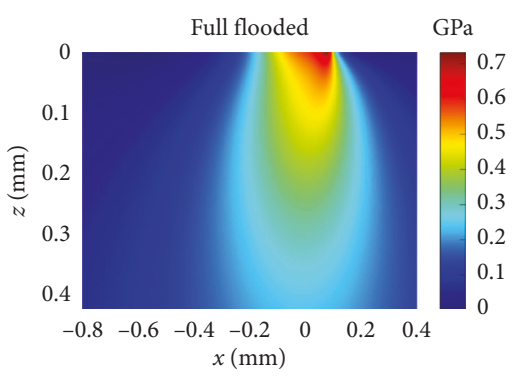

(c)

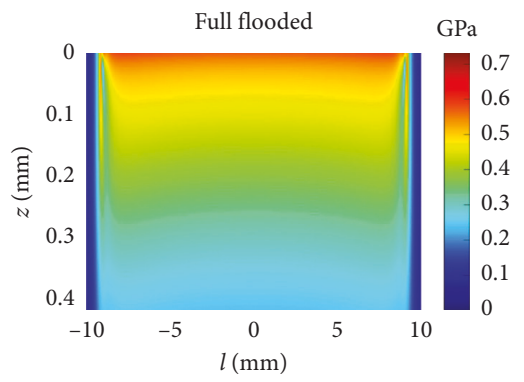

(f)

Figure 7: Distribution of von Mises stress on the sections $x=0$ and $y=0$ with different $h_{\text {oil }}$.

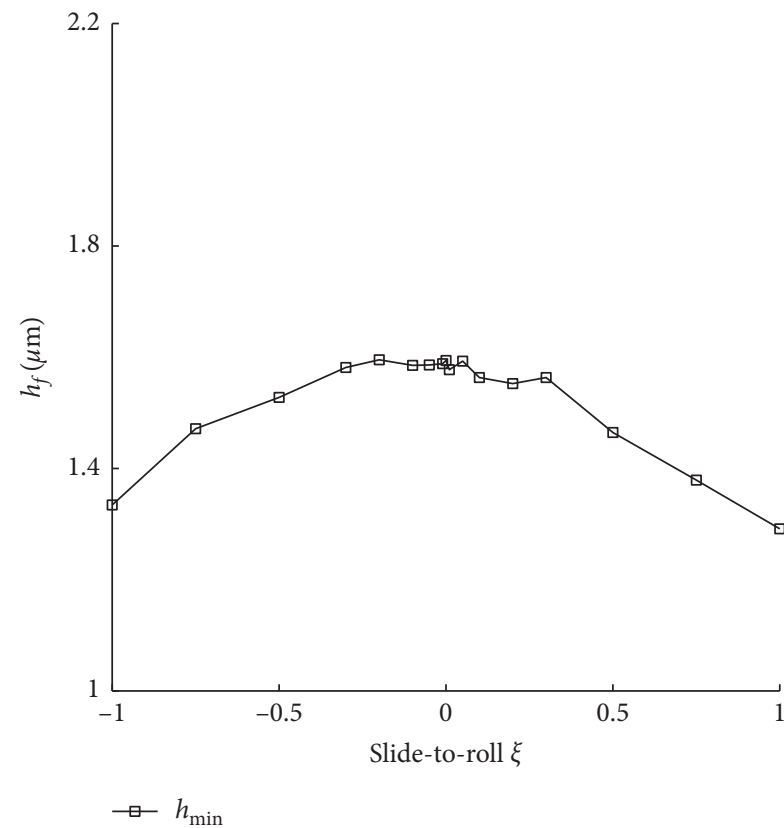

(a)

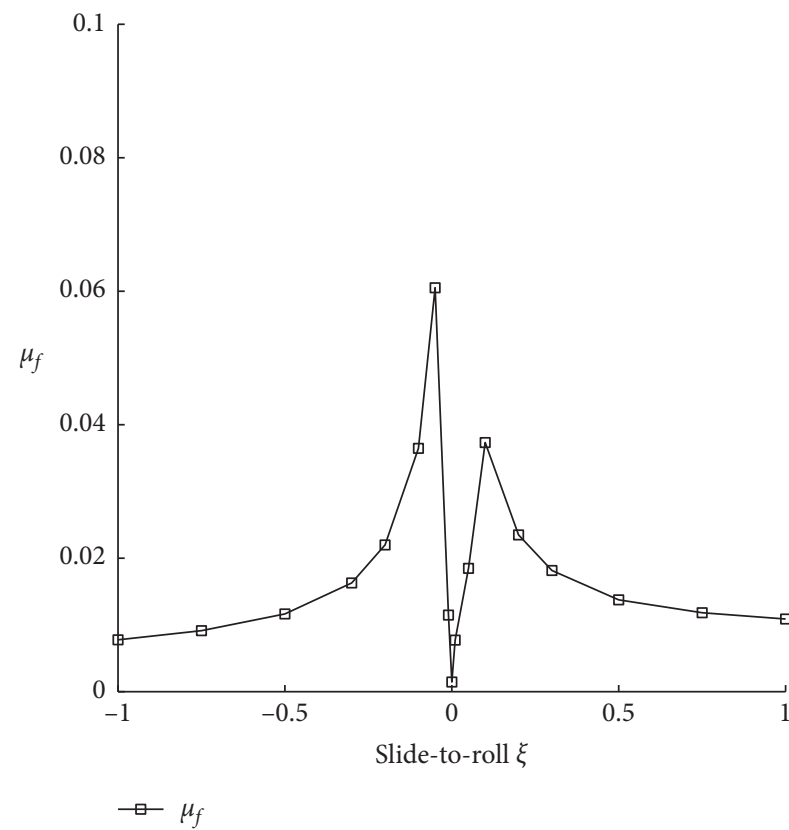

(b)

FIgURE 8: Effect of slide-to-roll ratio on the film thickness and friction coefficient.

pressure zone has been appropriately expanded. The corresponding film thickness distribution has been plotted in Figure 9(b).

Figure 10 shows the effects of SRR on the fatigue life under the starved lubrication condition. It illustrates that the distribution of fatigue life versus the SRR acts like a "W" shape. As the SRR ranges from 0.0 to \pm 1.0 , the fatigue life decreases firstly and then increases, which is contrary to the change trend of friction coefficient with the SRR. It is revealed that the higher fatigue life has been obtained during the pure rolling period and larger SRR value under the example cases. This is because that the adopted fatigue model is in the stress-based mode, as expressed in equation (17). The subsurface stress field is determined by the pressure and shear stress on the interface. As shown in Figure 9(a), the SRR has little influence on the pressure distribution. 


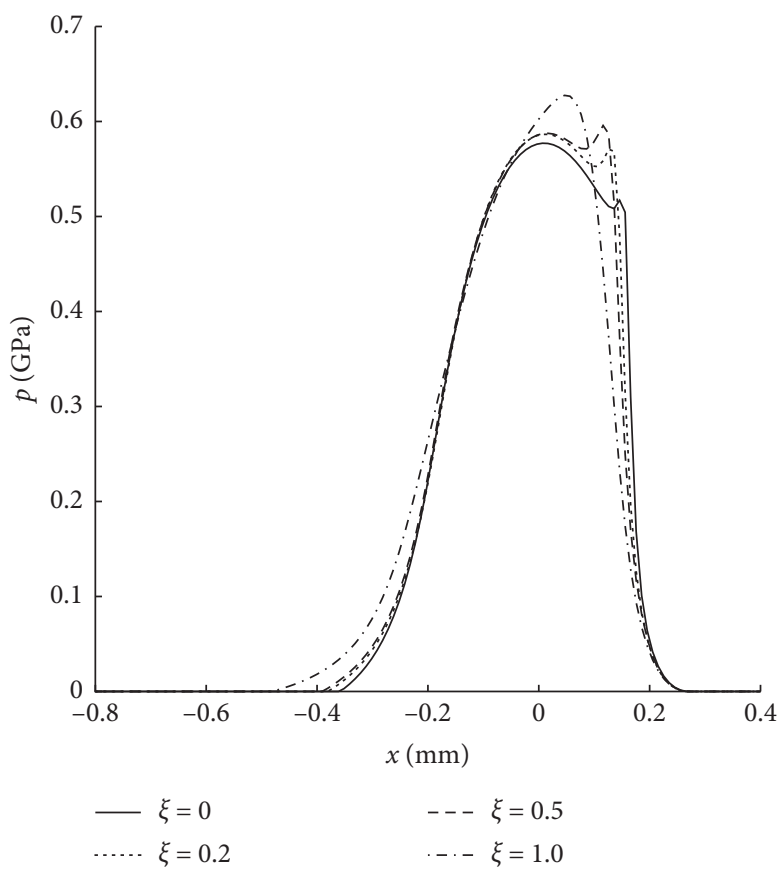

(a)

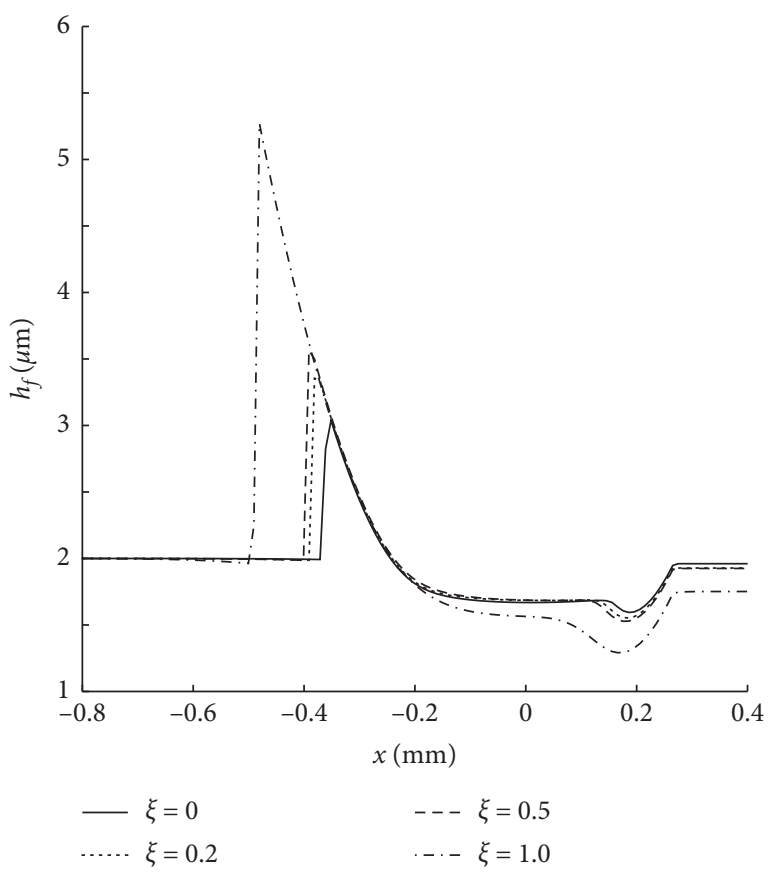

(b)

FIgURE 9: Distribution of pressure and film thickness with different $\xi$ on the section $y=0$.

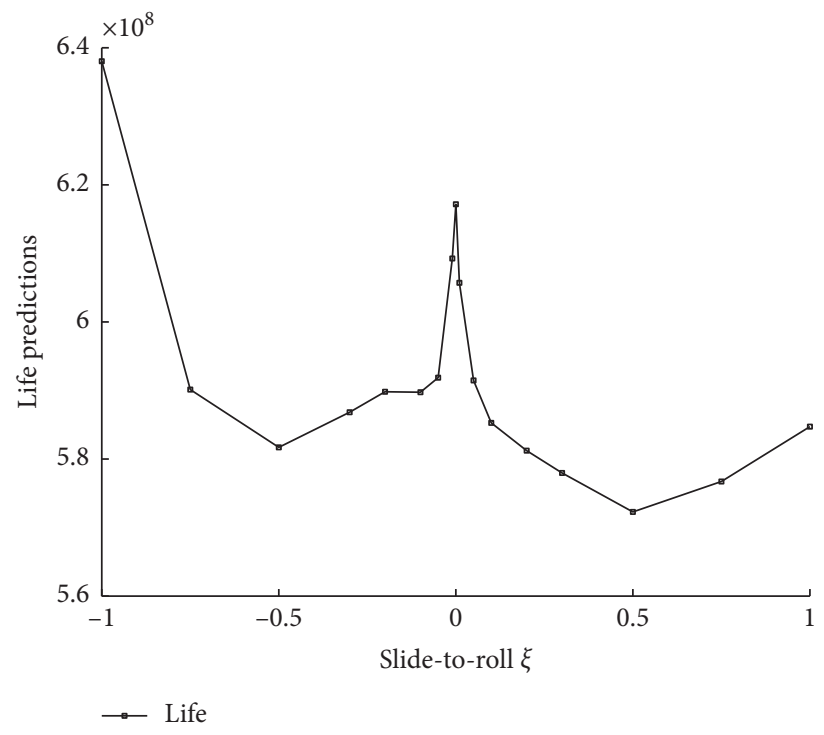

FIGURE 10: Effect of slide-to-roll ratio on the fatigue life.

However, the variation of friction coefficient is significant with the change of SRR value, as shown in Figure 8(b). In equations (15) and (16), the shear stress is positively correlated with the friction coefficient. The larger friction coefficient corresponds to the larger shear stress at the interface. Besides, Figure 10 shows that the negative and positive slid-to-roll ratios have different influences on contact fatigue life. This is due to the negative slip which makes the entrainment velocity increase and the sliding velocity increase more obviously. Under the coupling effect of entrainment velocity and thermal effect, the interfacial shear force with negative slip is smaller than that with positive slip. This conclusion is consistent with reference [26].

Figure 11 shows the distribution of subsurface stress field along the $z$ direction on the sections $x=0$ and $y=0$ with the SRR $\xi=0.0,0.5,1.0$. It can be seen from Figure 11 that the stress field distribution is similar, and the maximum stress value is $0.57 \mathrm{GPa}, 0.61 \mathrm{GPa}$, and $0.62 \mathrm{GPa}$, respectively. Due to the higher second pressure peak in 


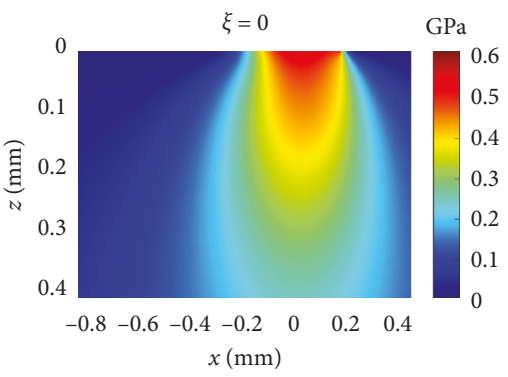

(a)

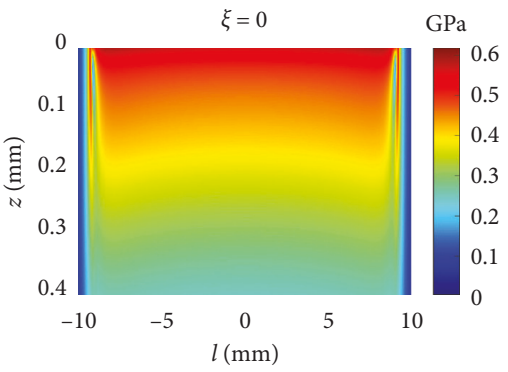

(d)

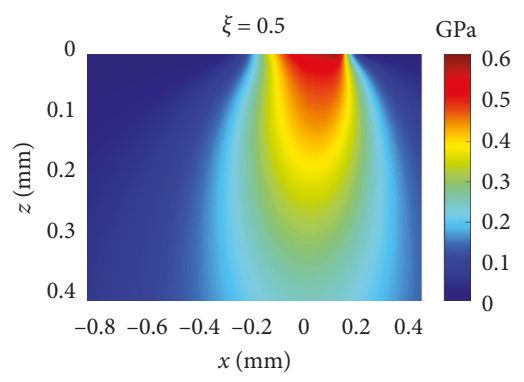

(b)

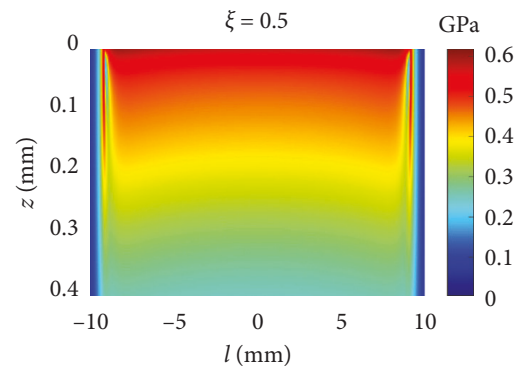

(e)

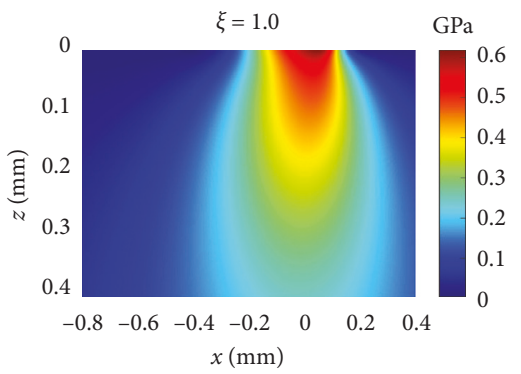

(c)

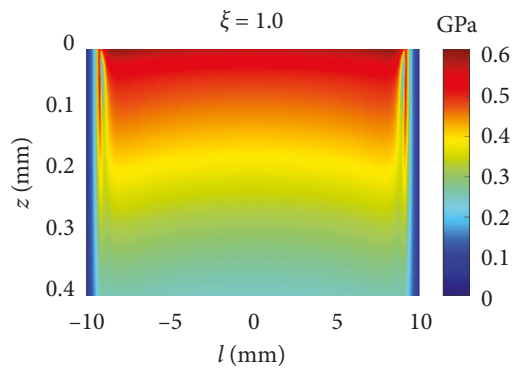

(f)

FIgURe 11: Distribution of von Mises stress on the sections $x=0$ and $y=0$ with different slide-to-roll ratio.

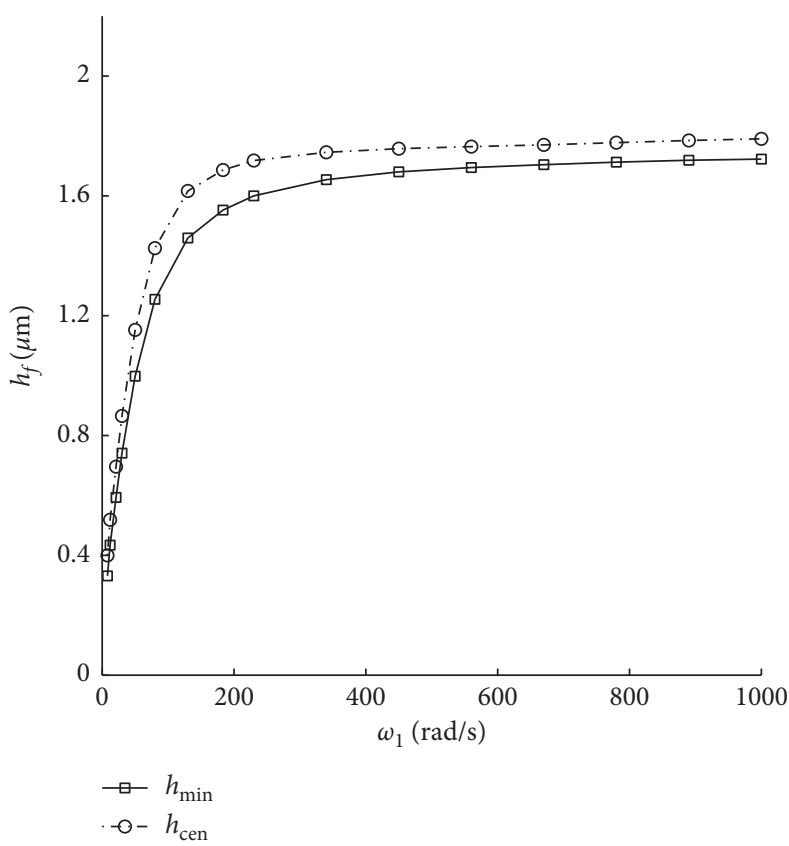

(a)

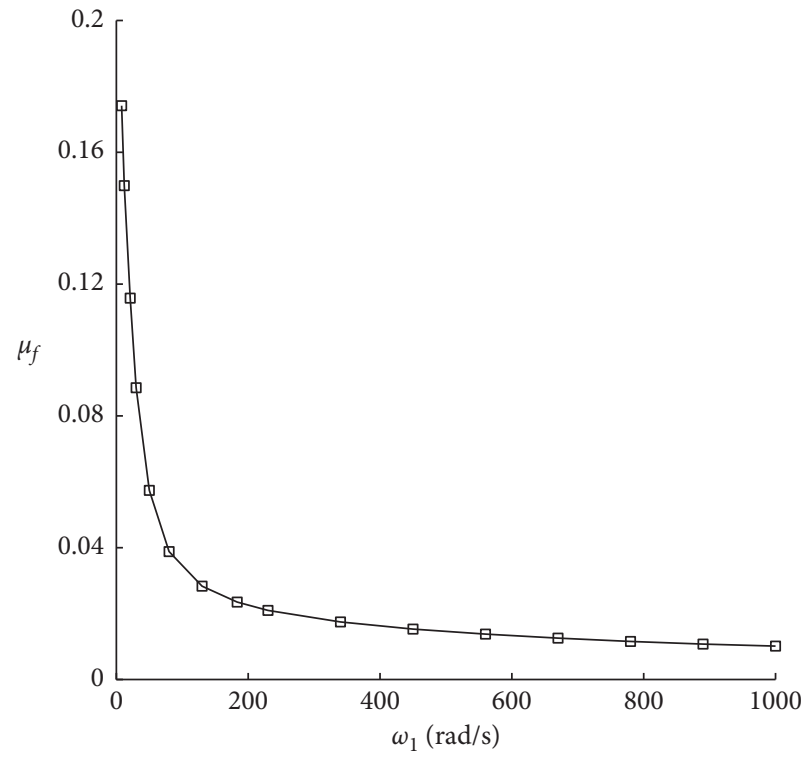

(b)

FIgURE 12: Effect of angular velocity on the film thickness and friction coefficient.

Figure 9(a), the value of stress field increases in the inlet region in Figures 11(a)-11(c). It indicates that the increase of SRR leads to increase in the subsurface stress peak value.

4.4. Effect of Angular Velocity. Similarly, the effects of angular velocity have been investigated, and the results are plotted in Figures 13-15. The corresponding parameters are the inlet oil-supply thickness $h_{\text {oil }}=2.0 \mu \mathrm{m}$ and SRR $\xi=0.2$. Figure 12 shows the effects of angular velocity on the film thickness and friction coefficient. Figure 12(a) reveals that as the angular velocity goes up, the film thickness first goes up remarkably and then approaches a certain critical value due to the constant inlet oil-supply thickness. The critical value of central film thickness is slightly lower than that of the inlet 


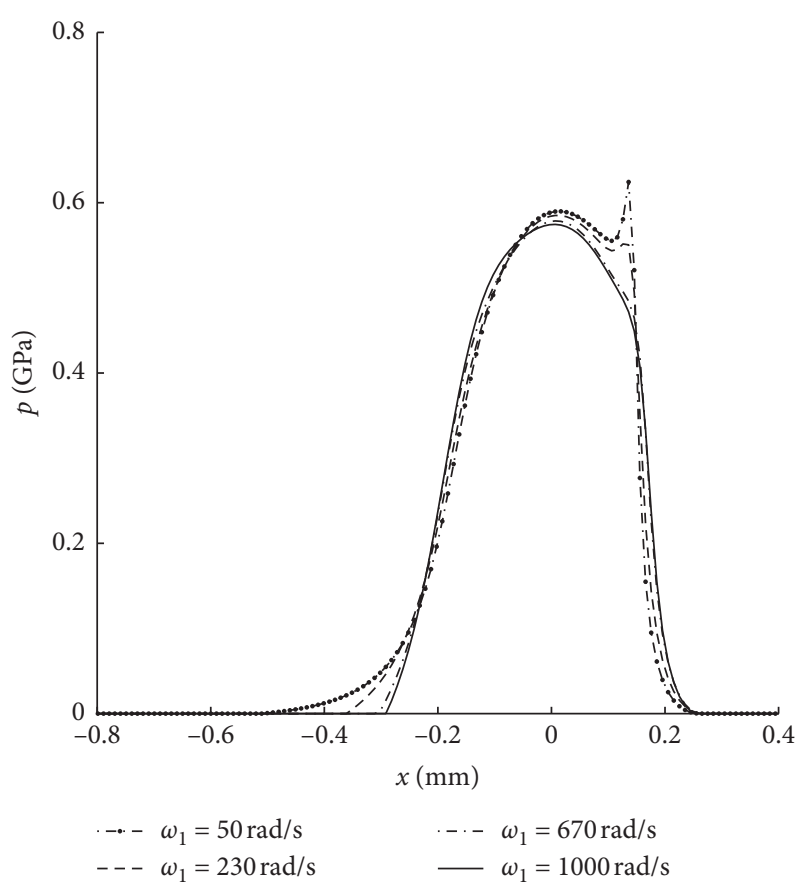

(a)

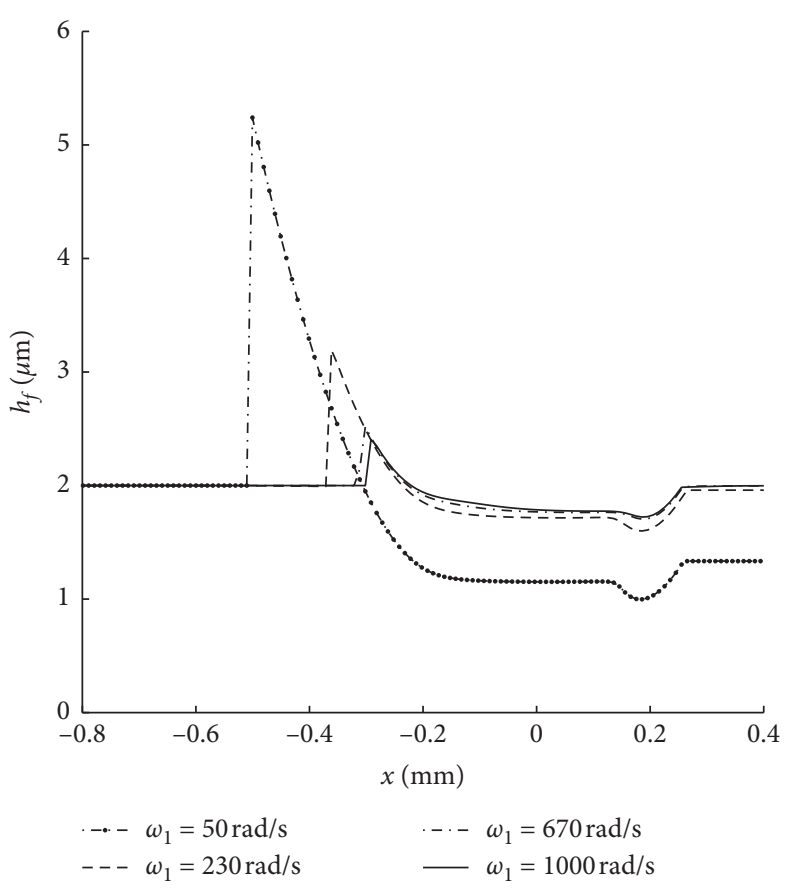

(b)

FIGURE 13: Distribution of pressure and film thickness with different angular velocities on the section $y=0$.

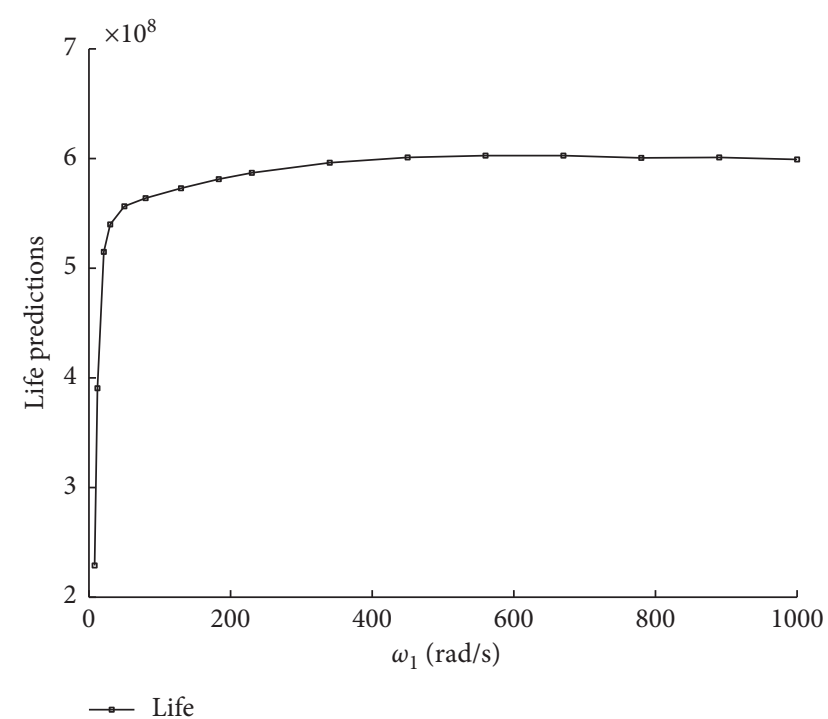

FIgURE 14: Effect of angular velocity on the fatigue life.

oil-supply thickness. Figure 12(b) plots the variation of friction coefficient with change of angular velocity. The variation of friction coefficient is consistent with that of the film thickness.

Figure 13 shows the distribution of pressure and film thickness on the section $y=0$. It can be observed that as the angular velocity is increased from 50 to $230 \mathrm{rad} / \mathrm{s}$, the film thickness goes up significantly. When the angular velocity is further increased to $1000 \mathrm{rad} / \mathrm{s}$, the increase of film thickness is limited due to the limitation of inlet oil-supply thickness. Meanwhile, the exit constriction becomes flatter and almost all the inlet oil-supply layer enters the contact area. The pressure distribution shown in Figure 13(a) appears to be anomalous. It indicates that as the angular velocity goes up, the effective pressure area and second pressure peak go down simultaneously. The similar conclusions have been reported in Ref. [6]. This is because with the increasing angular velocity, the gap between two contact surfaces becomes larger. The limitation inlet oilsupply layer is insufficient to fill the corresponding pressure area for the fully flooded lubrication.

Figure 14 shows the influence of angular velocity on the fatigue life of finite line contact with the starved lubrication. It can be seen from Figure 14 that with the increase of angular velocity, the fatigue life increases firstly and then tends to a constant. When the angular velocity is extremely low, the effect of angular velocity on the fatigue life is significant. It indicates that the inlet oilsupply layer is insufficient in these cases. As the angular velocity increases further, the contact interface becomes the starved lubrication. So, the angular velocity has little effect on the fatigue life at the high angular velocity range. Figure 15 shows the subsurface stress field distribution of finite line contact with different angular velocity. It can be seen from Figure 15 that, with the increase of angular velocity, the subsurface stress decreases. At the low angular velocity, the subsurface stress concentration is obvious. 


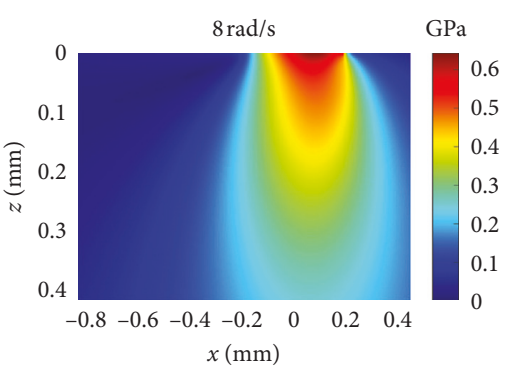

(a)

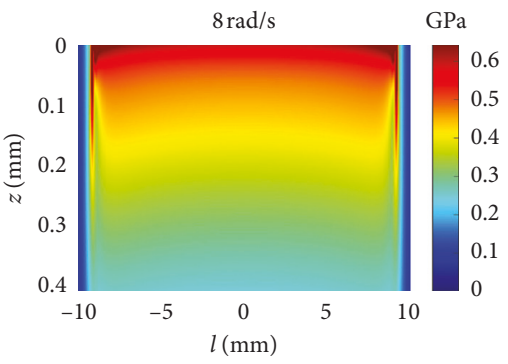

(d)

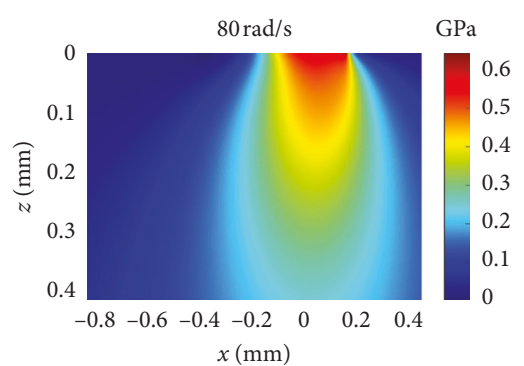

(b)

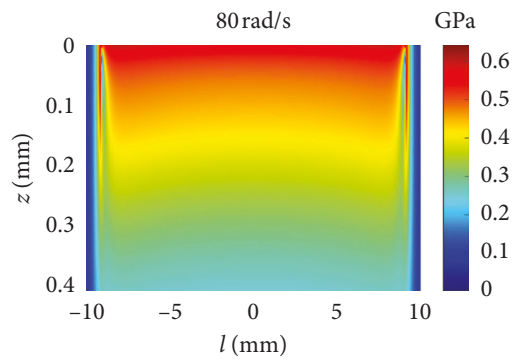

(e)

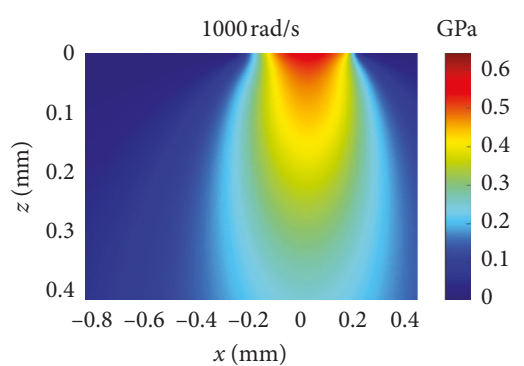

(c)

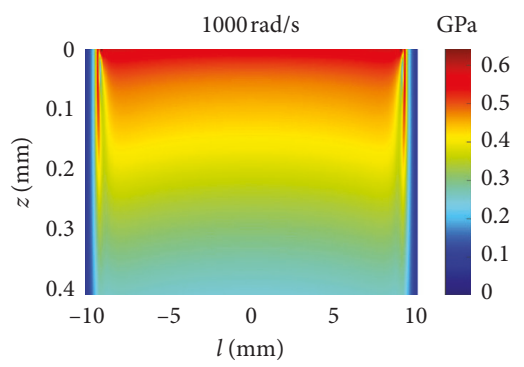

(f)

Figure 15: Distribution of von Mises stress on the section $x=0$ and $y=0$ with different angular velocity.

\section{Conclusions}

In this paper, a thermal EHL model of finite line contact under the starved lubrication has been established. Based on the proposed model, the effect of inlet oil-supply thickness and working conditions on the lubrication performance and fatigue life has been evaluated. Conclusions can be obtained as follows:

(1) With the increases of inlet oil-supply thickness, the film thickness increases firstly and then tends to be stable. The exit constriction becomes significant and the second pressure peak increases. The effective pressure area enlarges and the lubrication state tends to the fully flooded condition. Meanwhile, the contact pair has the optimum inlet oil-supply thickness which is related to the corresponding working conditions. The fatigue life of the contact pairs increases firstly and then tends to a certain value with the increase of inlet oil-supply thickness. When the contact pair is in a state of severely starved lubrication, the fatigue life is about $15 \%$ lower than that of full-film lubrication.

(2) With the SRR changes from pure rolling to sliding gradually, the second pressure peak increases and moves towards the inlet region. As the SRR changes from $\xi=0$ to $\xi= \pm 1$, the film thickness decreases and the friction coefficient increases firstly and then decreases. The variation of fatigue life is opposite to that of friction coefficient. As the slide-roll ratio goes up, the fatigue life decreases firstly and then increases. It indicates that the influence of thermal effect on the surface shear force has a great influence on the fatigue life.
(3) The example cases presented above have demonstrated that, due to the limitation of inlet oil-supply thickness, with the increase of angular velocity, the effective pressure area and second pressure peak go down simultaneously. In addition, the exit constriction becomes flatter and the film thickness tends to be a critical value. The friction coefficient first decreases sharply and then slowly goes down to remain unchanged basically. The angular velocity has great influence on the fatigue life during the lower angular velocity range. As the angular velocity increases, the fatigue life increases at first and then tends to a constant value.

\section{Nomenclature}

$c_{1}, c_{2}: \quad$ Specific heats of solids $(\mathrm{J} /(\mathrm{Kg} \cdot \mathrm{K}))$

$c_{\mathrm{f}}: \quad$ Specific heat of lubricant $(\mathrm{J} /(\mathrm{Kg} \cdot \mathrm{K}))$

$E^{\prime}: \quad$ Equivalent elastic modulus $(\mathrm{GPa})$

$h$ : Total geometric gap $(\mu \mathrm{m})$

$h_{\text {cen: }}$ Central film thickness on section $y=0(\mu \mathrm{m})$

$h_{\mathrm{g}}$ : $\quad$ Geometric gap $(\mu \mathrm{m})$

$h_{\text {min }}$ : Minimum film thickness on section $y=0(\mu \mathrm{m})$

$h_{\text {oil }}$ : Inlet oil-supply thickness $(\mu \mathrm{m})$

$k_{1,2}$ : Thermal conductivities of solids $(\mathrm{W} /(\mathrm{m} \cdot \mathrm{K}))$

$k_{\mathrm{f}}: \quad$ Thermal conductivity of lubricant $(\mathrm{W} /(\mathrm{m} \cdot \mathrm{K}))$

$l$ : Total length $(\mathrm{mm})$

$l_{x}$ : Modification length $(\mathrm{mm})$

$N: \quad$ Fatigue life (dimensionless)

$p: \quad$ Pressure $(\mathrm{GPa})$

$r_{1}, r_{2}$ : Modification radius $(\mathrm{mm})$

$R_{1}, R_{2}$ : Roller radius ( $\mathrm{mm}$ )

$S: \quad$ Probability of survival (dimensionless)

T: $\quad$ Temperature (K) 
$T_{0}$ : $\quad$ Ambient temperature $(\mathrm{K})$

$u_{1}, u_{2}$ : Surface velocity of two rollers $(\mathrm{mm} / \mathrm{s})$

$u_{\mathrm{e}}: \quad$ Entrainment velocity $(\mathrm{mm} / \mathrm{s})$

$u_{\mathrm{s}}$ : $\quad$ Sliding velocity $(\mathrm{mm} / \mathrm{s})$

$x, y, z$ : Coordinate system (dimensionless)

$\alpha: \quad$ Viscosity-pressure coefficient $\left(\mathrm{GPa}^{-1}\right)$

$\beta_{T}$ : Viscosity-temperature coefficient $\left(\mathrm{K}^{-1}\right)$

$\rho_{0}$ : $\quad$ Ambient density of lubricant $\left(\mathrm{Kg} / \mathrm{m}^{3}\right)$

$\rho_{1}, \rho_{2}$ : Density of solids $\left(\mathrm{Kg} / \mathrm{m}^{3}\right)$

$\eta_{0}: \quad$ Ambient viscosity of lubricant (Pa.s)

$\eta^{*}: \quad$ Equivalent viscosity $(\mathrm{Pa} \cdot \mathrm{s})$

$\theta: \quad$ Partial oil film ratio (dimensionless)

$\xi: \quad$ Slide-to-roll ratio (dimensionless)

$\omega_{1}, \omega_{2}$ : Angular velocity of two rollers ( $\left.\mathrm{rad} / \mathrm{s}\right)$

$\tau_{1}$ : $\quad$ Eyring stress value $(\mathrm{MPa})$

$\tau_{x}: \quad$ Surface shear stress $(\mathrm{MPa})$

$\sigma: \quad$ Subsurface stress field (GPa).

\section{Data Availability}

The data used to support the findings of this study are available from the corresponding author upon request.

\section{Conflicts of Interest}

The authors declare that there are no conflicts of interest regarding the publication of this paper.

\section{Acknowledgments}

This project was supported by the National Key R\&D Program of China (Grant nos. 2017YFD0700905 and 2017YFD0701105-03).

\section{References}

[1] L. D. Wedeven, D. Evans, and A. Cameron, "Optical analysis of ball bearing starvation," Journal of Lubrication Technology, vol. 93, no. 3, pp. 349-361, 1971.

[2] F. Chevalier, A. A. Lubrecht, P. M. E. Cann, F. Colin, and G. Dalmaz, "Film thickness in starved EHL point contacts," Journal of Tribology, vol. 120, no. 1, pp. 126-133, 1998.

[3] H. G. Elrod, "A cavitation algorithm," Journal of Lubrication Technology, vol. 103, no. 3, pp. 350-354, 1981.

[4] P. Yang, J. Wang, and M. Kaneta, "Thermal and non-Newtonian numerical analyses for starved EHL line contacts," Journal of Tribology, vol. 128, no. 2, pp. 282-290, 2006.

[5] C. Yin, P. Yang, H. Tan, and J. Wang, "Thermal elastohydrodynamic lubrication of starved elliptical contacts," Tribology International, vol. 42, no. 6, pp. 964-974, 2009.

[6] X. Liu and P. Yang, "Numerical analysis of the oil-supply condition in isothermal elastohydrodynamic lubrication of finite line contacts," Tribology Letters, vol. 38, no. 2, pp. 115-124, 2010.

[7] W.-Z. Wang, S. Li, D. Shen, S. Zhang, and Y.-Z. Hu, "A mixed lubrication model with consideration of starvation and interasperity cavitations," Proceedings of the Institution of Mechanical Engineers, Part J: Journal of Engineering Tribology, vol. 226, no. 12, pp. 1023-1038, 2012.

[8] A. Mihailidis, K. Agouridas, and K. Panagiotidis, "NonNewtonian starved thermal-elastohydrodynamic lubrication of finite line contacts," Tribology Transactions, vol. 56, no. 1, pp. 88-100, 2013.

[9] A. Parinam and R. Karan, "Analysis of starved EHL line contacts for lubricants with linear pressure viscosity dependence," International Journal of Advancements in Technology, vol. 5, no. 2, pp. 11-27, 2014.

[10] M. Masjedi and M. M. Khonsari, "A study on the effect of starvation in mixed elastohydrodynamic lubrication," Tribology International, vol. 85, pp. 26-36, 2015.

[11] D. Zhu, Q. J. Wang, and N. Ren, "Pitting life prediction based on a 3-D line contact mixed EHL analysis and subsurface von Mises stress calculation," ASME Journal of Tribology, vol. 131, no. 4, pp. 1-8, 2009.

[12] A. Torabi, S. Akbarzadeh, and M. R. Salimpour, "Mixed Thermo elastohydrodynamic lubrication analysis of finite length cam and follower mechanism," Journal of $\mathrm{Me}$ chanical Science and Technology, vol. 30, no. 3, pp. 12951303, 2016.

[13] M. Liu, C. Wu, and C. Yan, "Predicting fatigue life for finite roller contacts based on a mixed EHL model using realistic surface roughness," Journal of Mechanical Science and Technology, vol. 31, no. 7, pp. 3419-3428, 2017.

[14] H. Liu, C. Zhu, Z. Sun, and C. Song, "Starved lubrication of a spur gear pair," Tribology International, vol. 94, pp. 52-60, 2016.

[15] H. Liu, C. Zhu, Z. Sun, Y. Zhang, and C. Song, "Coefficient of friction of a starved lubricated spur gear pair," Journal of Mechanical Science and Technology, vol. 30, no. 5, pp. 21712177, 2016.

[16] W. Pu, D. Zhu, and J. Wang, "A starved mixed elastohydrodynamic lubrication model for the prediction of lubrication performance, friction and flash temperature with arbitrary entrainment angle," ASME Journal of Tribology, vol. 140, no. 3, pp. 31501-31512, 2018.

[17] P. Yang and S. Wen, "A generalized reynolds equation for non-newtonian thermal elastohydrodynamic lubrication," Journal of Tribology, vol. 112, no. 4, pp. 631-636, 1990.

[18] C. J. A. Roelands, W. O. Winer, and W. A. Wright, "Correlational aspects of the viscosity-temperature-pressure relationship of lubricating oils ( $\mathrm{dr}$ in dissertation at technical university of delft, 1966)," Journal of Lubrication Technology, vol. 93, no. 1, pp. 209-210, 1971.

[19] D. Dowson and G. R. Higginson, Elastohydrodynamic Lubrication, the Fundamentals of Roller and Gear Lubrication, Pergamon, Oxford, UK, 1966.

[20] H. Eyring, "Viscosity, plasticity, and diffusion as examples of absolute reaction rates," The Journal of Chemical Physics, vol. 4, no. 4, pp. 283-291, 1936.

[21] H. Qiao, H. P. Evans, and R. W. Snidle, "Comparison of fatigue model results for rough surface elastohydrodynamic lubrication," Proceedings of the Institution of Mechanical Engineers, Part J: Journal of Engineering Tribology, vol. 222, no. 3, pp. 381-393, 2008.

[22] E. V. Zaretsky, "Fatigue criterion to system design, life, and reliability," Journal of Propulsion and Power, vol. 3, no. 1, pp. 76-83, 1987.

[23] Y. Liu, Q. J. Wang, W. Wang, Y. Hu, and D. Zhu, "Effects of differential scheme and mesh density on EHL film thickness in point contacts," Journal of Tribology, vol. 128, no. 3, pp. 641-653, 2006.

[24] S. Liu and Q. Wang, "Studying contact stress fields caused by surface tractions with a discrete convolution and fast fourier transform algorithm," Journal of Tribology, vol. 124, no. 1, pp. 36-45, 2002. 
[25] V. Simon, "Elastohydrodynamic lubrication of hypoid gears," Journal of Mechanical Design, vol. 103, no. 1, pp. 195-203, 1981.

[26] C.-M. Everitt and B. Alfredsson, "Surface initiation of rolling contact fatigue at asperities considering slip, shear limit and thermal elastohydrodynamic lubrication," Tribology International, vol. 137, pp. 76-93, 2019. 


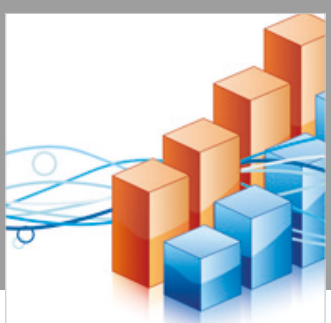

Advances in

Operations Research

\section{-n-m}
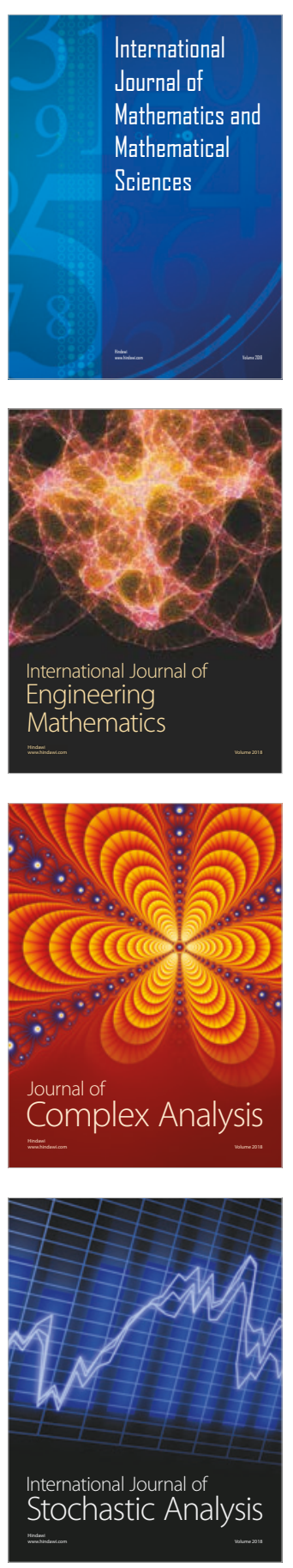
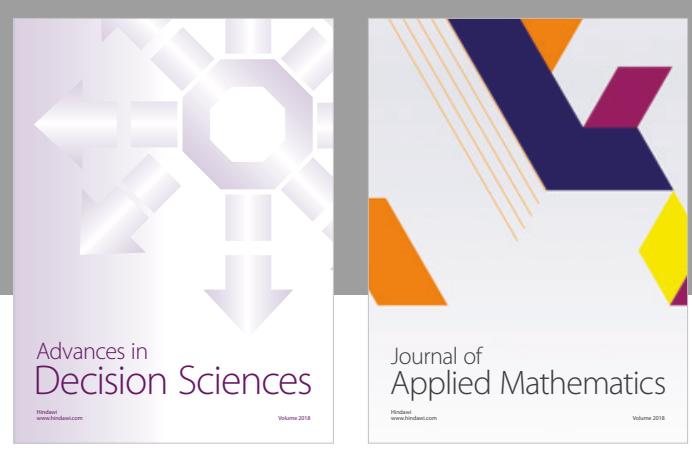

Journal of

Applied Mathematics
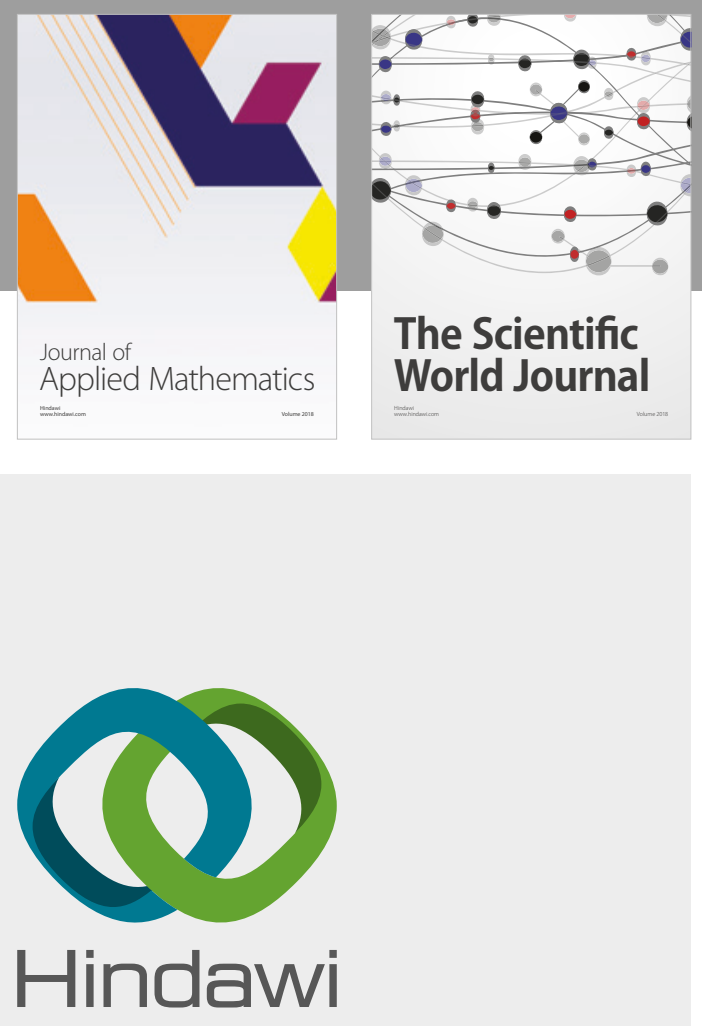

Submit your manuscripts at

www.hindawi.com

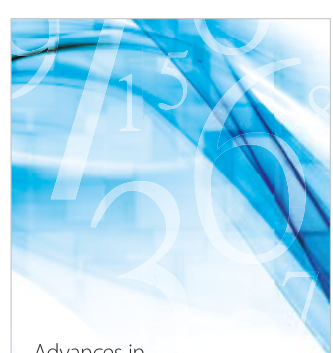

Advances in
Numerical Analysis
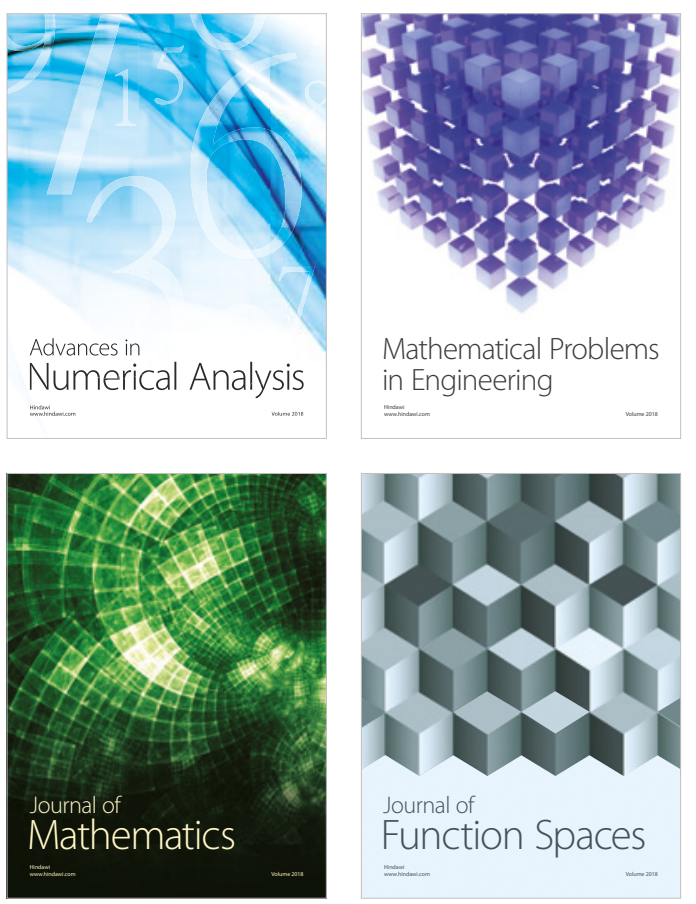

Mathematical Problems in Engineering

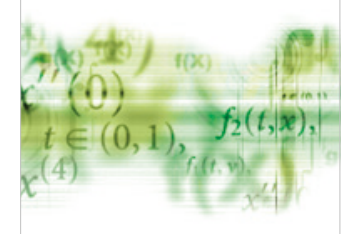

International Journal of

Differential Equations

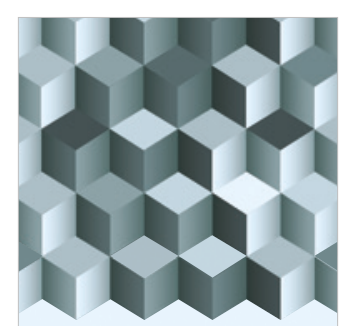

Journal of

Function Spaces

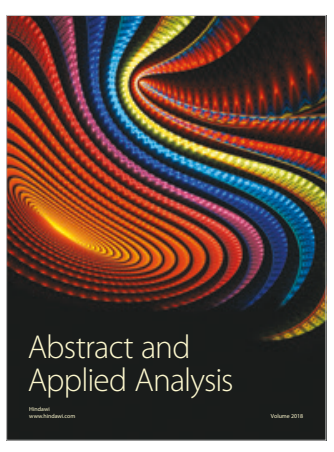

The Scientific

World Journal

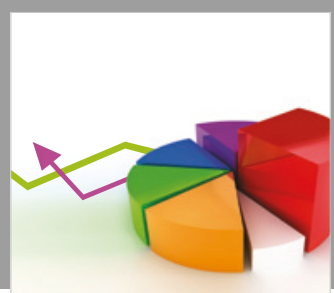

Journal of

Probability and Statistics
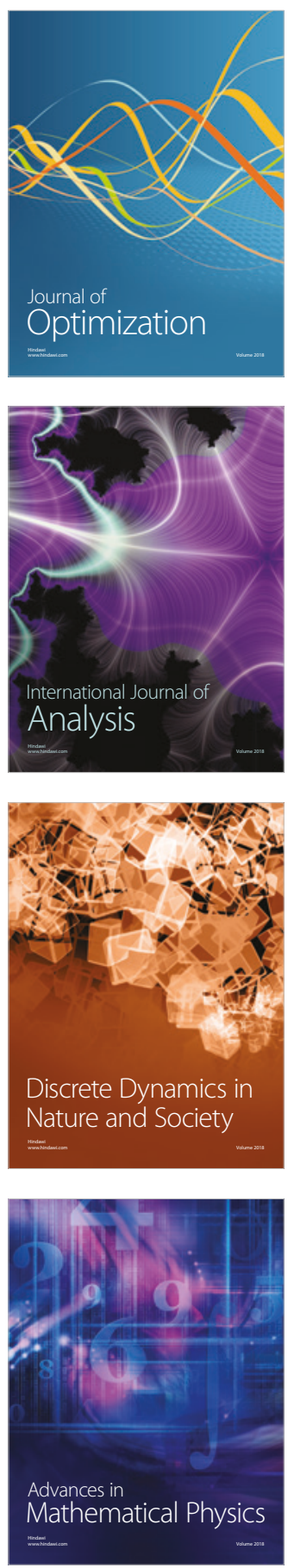